\title{
Validation of the NEMO-ERSEM operational ecosystem model for the North West European Continental Shelf
}

\author{
K. P. Edwards ${ }^{1, *}$, R. Barciela ${ }^{1}$, and M. Butenschön ${ }^{2}$ \\ ${ }^{1}$ Met Office, Exeter, UK \\ ${ }^{2}$ Plymouth Marine Laboratory, Plymouth, UK \\ *now at: Environment Agency, Exeter, UK
}

Correspondence to: K. P. Edwards (karen.edwards@environment-agency.gov.uk)

Received: 12 January 2012 - Published in Ocean Sci. Discuss.: 22 February 2012

Revised: 18 October 2012 - Accepted: 21 October 2012 - Published: 21 November 2012

\begin{abstract}
This paper details updates to the Met Office's operational coupled hydrodynamic-ecosystem model from the $7 \mathrm{~km}$ Medium-Resolution Continental Shelf - POLCOMSERSEM (MRCS-PE) system (Siddorn et al., 2007) to the $7 \mathrm{~km}$ Atlantic Margin Model NEMO-ERSEM (AMM7-NE) system. We also provide a validation of the ecosystem component of the new operational system. Comparisons have been made between the model variables and available in situ, satellite and climatological data. The AMM7-NE system has also been benchmarked against the MRCS-PE system. The transition to the new AMM7-NE system was successful and it has been running operationally since March 2012 and has been providing products through MyOcean (http://www.myocean.eu.org) since that time. The results presented herein show the AMM7-NE system performs better than the MRCS-PE system with the most improvement in the model nutrient fields. The problem of nutrient accumulation in the MRCS-PE system appears to be solved in the new AMM7-NE system with nutrient fields improved throughout the domain as discussed in Sect. 4. Improvements in model chlorophyll are also seen but are more modest.
\end{abstract}

\section{Introduction}

Continental shelf seas provide an important link between the land and the open ocean and mediate the transport of material such as nutrients, carbon, pollutants, and freshwater between them. The shelf seas are also the regions where most of the human interactions with the marine environment occur including leisure and recreation, aquaculture and fisheries, extraction of raw materials such as aggregates, oil and gas, and renewable energy (wind, wave, and tidal). These regions are highly productive with nutrient fluxes from both the open ocean and river runoff and are regions of generally rapid biogeochemical cycling (Gattuso et al., 1998). The shelf seas are a disproportionately important component of the marine environment: while they occupy less than $10 \%$ of the area of the world's oceans, they account for up to $30 \%$ of the ocean's primary production (Smith and Hollibaugh, 1993; Longhurst et al., 1995), include the major fisheries of the world (Pauly and Christensen, 1995), and may be important in global carbon budgets (Holt et al., 2009).

One important tool used to gain better understanding of the state of the shelf seas ecosystems is ecosystem models. These models have been developed for a wide range of applications from process-oriented models designed to gain better understanding of shelf seas biogeochemical cycles, nutrient fluxes and pathways (e.g. Proctor et al., 2003) to application-based models designed to improve understanding of the effects of such things as eutrophication (Nobre et al., 2005, and references therein), fish farms (Wild-Allen et al., 2010) and aquaculture (Tsagaraki et al., 2011), hypoxia (Russo et al., 2009) and harmful algal blooms (HABS, see McGillicuddy, 2010, and the Special Issue on GEOHAB Modelling). Coupled 3dimensional hydrodynamic-ecosystem models can simulate the biogeochemistry of coastal ecosystems and be used to explore a range of alternate situations or possible futures to provide a synthesis of how a particular ecosystem works (e.g. Moll and Radach, 2003; Popova et al., 2002) or to explore alternate states under a range of management scenarios (Petihakis et al., 2007; Wild-Allen et al., 2010). 
Operational ecosystem models allow the near real-time estimation of the state of the system and provide the only practical means of providing a real-time snapshot of the complex 4-dimensional structure of the shelf and shelf-edge waters including the connection between the shelf seas and the open ocean. Operational systems, in this context, describe automated systems that run regularly in real-time or near realtime such as that at the Met Office. These systems have been set up to provide support for scientific, coastal management and naval objectives, among others, in regional systems and use a variety of modelling tools and observations. Operational (or pre-operational) systems in the United States are being set up to provide regional forecasts of harmful algal blooms and water quality in the Great Lakes, coral bleaching in relation to ocean water temperatures, and pink salmon harvest in Southeast Alaska (Green et al., 2009). Also in the United States, the Naval Research Laboratory (NRL) has implemented a coupled hydrodynamic-biogeochemical model in the Gulf of Mexico (the Gulf of Mexico Modelling System, GOMMS) on an operational basis (de Rada et al., 2009). In the Mediterranean, an operational forecast system which includes ecosystem modelling at both the basin scale and sub-regional and shelf scales has been developed and provides algal biomass forecasts, estimates of coastal sediment transport and is being used in fish stock assessments (Lazzari et al., 2010; Pinardi and Coppini, 2010). Roiha et al. (2010) present an operational ensemble approach to forecasting HABs in the Baltic Sea while Glibert et al. (2010) provide a review of forecasting models of HABs in eutrophic systems. Coupled hydrodynamic-ecosystem models are also being used operationally to forecast hypoxic events in the Adriatic (Russo et al., 2009) and Gulf of Mexico (Justic et al., 2007).

The MRCS-PE shelf seas hydrodynamic-ecosystem system has been run daily since 2007 at the UK Met Office. It is described and validated in Siddorn et al. (2007) and is based on the POLCOMS hydrodynamic model (described further below) and the ERSEM model for the marine ecosystem component. This model was used with Ferrybox data to evaluate the leak of phosphoric acid from the wreck of the MV Ece in the English Channel in 2006 (Kelly-Gerreyn et al., 2007). One important application of the shelf-seas coupled system is to provide support for the UK agencies responsible for ecosystem health, water quality monitoring and nuisance algal bloom prediction. The Met Office, Plymouth Marine Laboratory (PML) and the Environment Agency (EA) have been working on a joint project, AlgaRisk, designed to develop a forecasting tool as a demonstration service for forecasting water quality and nuisance algal blooms (Mahdon et al., 2010). The system has also been used as part of the European COastal-shelf sea Operational observing and Forecasting system (ECOOP; http://www.ecoop.eu) to provide ecosystem boundary conditions on an operational basis to European partners for regional models within the MRCS domain. Most recently, daily analysis and forecasts from the ERSEM biological variables for the North West European Shelf (NWS) are being delivered via the MyOcean project (www.myocean.eu.org) as part of the prototype for the GMES (Global Monitoring for Environment and Security) programme.

This paper details updates to the Met Office operational coupled hydrodynamic-ecosystem model for the NWS from the system described in Siddorn et al. (2007) along with a validation of the ecosystem component of the operational system. O'Dea et al. (2012) describes the transition to the NEMO system for the hydrodynamics while this paper concentrates on the relevant changes to the biogeochemical component, ERSEM. Comparisons have been made between the model variables and available in situ satellite and climatological data. It is important to note that the presented AMM7-NE system has emerged from previous systems and work that have suggested substantial changes to the operational setup which we are elaborating here (see Siddorn et al., 2007, which describes the MRCS-PE system). This work has confirmed that the changes are indeed improvements to the system which have a significant impact on the model quality. These improvements are carried through to the users of the operational products by the MyOcean system.

This paper is structured as follows. Section 2 provides a description of the new coupled AMM7-NE system highlighting differences from the MRCS-PE system described in Siddorn et al. (2007) along with the setup of the model hindcast runs, the data used for comparison and the metrics applied for skill assessment. Section 3 presents the results which are discussed in Sect. 4 and concluding remarks are provided in Sect. 5 .

\section{Materials and methods}

\subsection{System description}

With regard to the UK shelf-seas operational modelling at the UK Met Office, the underlying physical model has recently been transitioned to the NEMO (Madec, 2008; Storkey et al., 2010) framework adapted for use on the $7 \mathrm{~km}$ Atlantic Margin Model (AMM7) domain. This model has been coupled to the ERSEM (Baretta et al., 1995; Blackford et al., 2004) biogeochemical model. The AMM7-NE configuration includes the assimilation of sea surface temperature (SST) using an adaptation of the existing Forecasting Ocean Assimilation Model (FOAM; Martin et al., 2007) system suitable for use in the shelf seas.

Both the MRCS-PE and the AMM7-NE models are part of a system of one-way nested hydrodynamic operational models as shown in Fig. 1. This series of nested domains provides 3-D boundary conditions for the regional models (sea surface height, temperature, salinity and current fields). The model (in both the MRCS-PE and AMM7-NE) is forced at the surface by fluxes (three-hourly means of heat and moisture and 


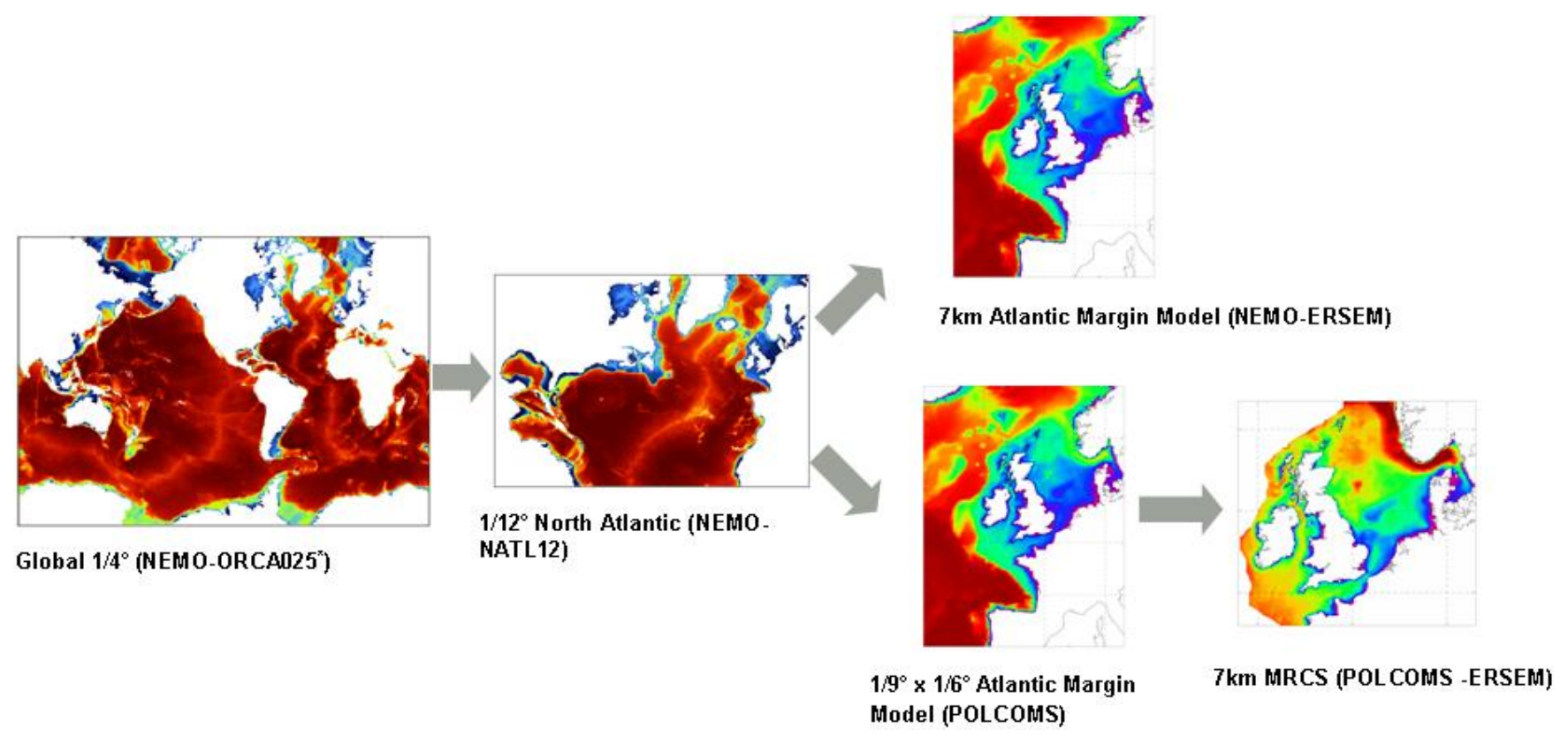

Fig. 1. The domains and nests used for the new NEMO (AMM7-NE, top) and POLCOMS (MRCS-PE, bottom) coupled systems. The colours indicate the depth of bathymetries.

hourly fluxes of winds and pressure) from the global Met Office Numerical Weather Prediction (NWP) model. The NWP model has a horizontal resolution of approximately $25 \mathrm{~km}$. River flow is specified for 320 European rivers (Young and Holt, 2007).

Both the domain and the hydrodynamic component have been changed for the new AMM7-NE. Previously, the coupled system was run on the MRCS domain covering the NWS from $12^{\circ} \mathrm{W}$ to $13^{\circ} \mathrm{E}$ and $48^{\circ} \mathrm{N}$ to $62^{\circ} \mathrm{N}$, as shown in Fig. 1 (bottom) in which the open boundary follows the $200 \mathrm{~m}$ depth contour around most of domain. The hydrodynamic component was the Proudman Oceanographic Laboratory (now National Oceanography Centre) Coastal-Ocean Model System (POLCOMS, Holt and James, 2001; Holt et al., 2005). The model resolution was approximately $7 \mathrm{~km}$ in the horizontal with $18 \mathrm{~S}$-coordinate levels in the vertical.

In the new AMM7-NE system, the domain covers the NWS and part of the North-East Atlantic Ocean (from approximately $40^{\circ} \mathrm{N}$ to $65^{\circ} \mathrm{N}$ and $20^{\circ} \mathrm{W}$ to $13^{\circ} \mathrm{E}$ ) as shown in Fig. 1 (top). The horizontal resolution of the coupled system has remained at approximately $7 \mathrm{~km}$ while the vertical levels have increased from 18 to 32 . The boundary conditions for the ecosystem model nutrients in AMM7-NE are provided by monthly World Ocean Atlas values (Garcia et al., 2010) with zero-flux boundary conditions used for the other variables. In the MRCS-PE system, the zero-flux boundary condition was applied to all ERSEM variables. A comparison of the POLCOMS and NEMO shelf physics is provided in O'Dea et al. (2012) and O'Neill et al. (2012).
In the new domain (AMM7), off-shelf areas were included to improve the dynamics on the shelf and the shelf-break exchange. It is clear that this domain with large impacts of highly dynamic open boundaries is not suitable for a detailed description of the off-shelf waters, but was designed in order to improve the representation of the continental shelf. A further extended domain of the North Atlantic, necessary for an appropriate description of the off-shelf areas (see also Holt et al., 2012), at this spatial resolution is currently out of scope for an operational system of the marine ecosystem, but is the subject of on-going research programmes (e.g. EUROBASIN) and may be considered for the next generation of the operational modelling suite. We are also investigating the one- or (eventually) two-way coupling of the AMM7-NE ERSEM model into a global biogeochemical model run preoperationally at the Met Office.

\subsubsection{Hydrodynamic model description}

NEMO was originally developed as an open ocean model and was missing many of the features such as tides needed to accurately model shelf-seas. The shelf adaptations to the NEMO system are described fully in O'Dea et al. (2012) and only a brief summary of those differences is presented herein. First, the shelf seas version of NEMO includes a fully non-linear free surface using a variable volume (Levier et al., 2007) which is important for modelling tides and surges. The second main departure of the NEMO shelf system from the open ocean is the use of terrain-following vertical coordinates in place of regular z-coordinates. Benefits from terrain following coordinates include maintaining high vertical 
resolution in the shelf, both in the surface and the bottom boundary layers. This is particularly useful when trying to capture both off shelf and on shelf dynamics, which would require a very high resolution z-level model. Such coordinates do have drawbacks, including dealing with horizontal pressure gradients errors, and vertical diffusion which needs special treatment not required in an open ocean model (Song and Haidvogel, 1994; O'Dea et al., 2012). In the NEMO system for the shelf seas, use is made of a hybrid $\mathrm{z}-\sigma$ model where the number of levels is decreased near particularly steep topography to prevent very steeply inclined model levels (see O'Dea et al., 2012, and references therein). The third major difference in the NEMO configuration on the shelf is the use of a more sophisticated turbulence scheme, necessary for the modelling of complex interactions such as seasonal stratification, tidal fronts and haline stratification from river plumes. A generic length-scale (Umlauf and Burchard, 2003) framework is used. This uses a k- $\varepsilon$ turbulence closure scheme and the Craig and Banner (1994) surface wave mixing parameterisation.

The river scheme in NEMO has been updated so temperature, salinity, nutrients and sediment boundary conditions at river inflow points can be specified flexibly to better represent the vertical structure of different river outflows. The rivers have been modified to allow for a depth at which to mix the incoming flow rather than mixing the river flow through the entire water column as is done in the POLCOMS system. The river input data has not changed between the two systems and represents climatological values. In the current configuration, the temperature of the river water is not included (i.e. a zero flux gradient condition is applied) and the river flow only is specified (i.e. the river input is assumed to be of water of zero salinity). The Baltic flows, through the Belt region, are treated as additional rivers with specification of fluxes including temperature, salinity and sediments.

Finally, the light attenuation formulation, affecting both the hydrodynamics and ecosystem variables, in NEMO has been modified. The light attenuation is a very simple scheme following POLCOMS, which is also used in ERSEM, that attempts to account for reduced near coast visibility by decreasing the depth to which light penetrates as a function of the bathymetry (Baretta et al., 1988).

\subsubsection{Ecosystem model description}

The ecosystem component of the coupled operational system is ERSEM (Baretta et al., 1995; Blackford et al., 2004) which is one of the most complex lower trophic-level marine ecosystem models. ERSEM is a generic model that parameterises physiological processes and population dynamics through changes in biomass in both the pelagic and benthic ecosystems and the coupling between them in terms of the significant biogeochemical processes affecting the stoichiometrically variable flow of the main constituents of the system: carbon, nitrogen, phosphorus and silicon. It uses a functional group approach to divide the ecosystem into aggregated groups representing basic functional roles (production, consumption and decomposition) and sub-divided according to size and feeding method. The pelagic module in ERSEM includes one bacterial group, four phytoplankton and three zooplankton functional groups, a fully resolved diurnal cycle, and variable carbon to chlorophyll ratios. In the benthos, ERSEM includes both aerobic and anaerobic bacteria, suspension feeders, bottom feeders and the meiobenthos. The parameter set used in the MRCS-PE operational system is from Blackford et al. (2004) while the new AMM7-NE system includes modifications as described in Butenschön et al. (2012). Validation of intermediate results with the old parameterisation on the related POLCOMS-AMM configuration (Holt et al., 2012; Butenschön et al., 2012) have shown chlorophyll $a$ values which are too high throughout the domain. Comparison with chlorophyll : carbon data (Geider et al., 1997; Sathyendranath et al., 2009) has suggested a too high maximum chlorophyll to carbon ratio $\left(\phi_{\max }\right)$ as a cause leading to the new parameterisation. The new value for $\phi_{\max }$ is $0.035 \mathrm{mg} \mathrm{Chl} \mathrm{mg} \mathrm{C}^{-1}$ with $0.025 \mathrm{mg} \mathrm{Chl} \mathrm{mg} \mathrm{C}^{-1}$ for $\phi_{\min }$. ERSEM now allows the flexibility for these parameters to vary by phytoplankton type, although they have not been set to do so in this setup.

Light attenuation within ERSEM is calculated using the attenuation contributions from seawater, various biological components and suspended (inorganic) sediment. The sediment contribution is provided through a coupled 3-D sediment model. The sediment model has successfully been coupled to POLCOMS (Souza et al., 2007) and, more recently, to NEMO. It consists of two user-defined sediment size classes described by characteristic settling velocities. Recently, the sediment size classes, settling velocities and critical erosion/deposition rates have been updated and equations to represent the sedimentary process of aggregation and disaggregation have been added (Sykes and Barciela, 2012).

As discussed by O'Dea et al. (2012) in terms of the hydrodynamic model, the $7 \mathrm{~km}$ resolution of the AMM7 domain is not sufficient to resolve the internal Rossby radius on the shelf, which is on the order of $4 \mathrm{~km}$, and is therefore insufficient to resolve the fine-scale physics on the shelf. This will also influence the sediment and biogeochemical fields in the coupled system including the chlorophyll $a$ concentration and distribution. The spreading and mixing of the river-based freshwater might also be insufficiently simulated in the $7 \mathrm{~km}$ model.

\subsection{Model hindcasts}

Hindcasts for calendar years 2007 and 2008 were run for both the MRCS-PE and the AMM7-NE. For the AMM7-NE hindcasts, the NEMO physical fields were spun up for a total of 2 years while the ERSEM and SPM fields were spun up for one year with the NEMO physics. The NEMO model was initialised with temperature and salinity fields which were 
interpolated from the operational North Atlantic FOAM system onto the AMM7 grid. The currents were allowed to spinup from rest. Due to the long spin-up time required for the ERSEM fields (both benthic and pelagic), the ERSEM restart used at the beginning of the NEMO-ERSEM one year spinup period was the final state from a POLCOMS-ERSEM simulation for the years 1960-2004 on the 12 km AMM domain (Butenschön et al., 2012). The sediment fields, at the start of the AMM7-NE one year spin-up, were initialised with a completely sediment-free water column and a uniform initial bed supply of $150 \mathrm{gm} \mathrm{m}^{-2}$ per active model grid point for each of the two size classes of sediment. For the MRCSPE hindcast, the POLCOMS fields were taken from the operational restart at the end of 2006. A one-year spin-up for this system, similar to the MRCS-PE system was performed with the initial bed sediment as above and with the ERSEM fields from the operational restart with the exception of a reset of the nutrient fields to remove the nutrient problems present in the operational system. From this, a two-year hindcast was produced.

\subsection{Datasets}

The MRCS-PE system provides a baseline target for the new system, so model results were compared with each other and with available data in the region and the World Ocean Atlas monthly nutrient climatology (Garcia et al., 2010).

Time series of in situ fluorescence (as a proxy for chlorophyll), nitrate and silicate data from four monitoring buoys (SmartBuoy) from the UK Centre for the Environment, Fisheries and Aquaculture Science (Cefas) were also used for comparison with model values. The SmartBuoy locations are Liverpool Bay $\left(53^{\circ} 32.0^{\prime} \mathrm{N}, 003^{\circ} 21.8^{\prime} \mathrm{W}\right)$, Oyster Ground $\left(54^{\circ} 25.0^{\prime} \mathrm{N}, 004^{\circ} 02.0^{\prime} \mathrm{E}\right)$, Warp Anchorage $\left(51^{\circ} 31.5^{\prime} \mathrm{N}\right.$, $\left.001^{\circ} 01.9^{\prime} \mathrm{E}\right)$ and West Gabbard $\left(51^{\circ} 59.0^{\prime} \mathrm{N}, 002^{\circ} 05.0^{\prime} \mathrm{E}\right)$. The Liverpool Bay, Warp Anchorage and West Gabbard sites are all relatively near-shore in water depths of $22 \mathrm{~m}, 15 \mathrm{~m}$ and $32 \mathrm{~m}$, respectively. The Warp Anchorage and West Gabbard buoys are situated in the Thames outflow region. The Oyster Ground buoy is further offshore in the southern North Sea and is part of a UK-Netherlands collaborative monitoring programme.

Time-series data from the Western Channel Observatory station L4 have also been used (Smyth et al., 2010). The L4 station $\left(50^{\circ} 15^{\prime} \mathrm{N}, 04^{\circ} 13^{\prime} \mathrm{W}\right)$ is approximately $10 \mathrm{~km}$ off Plymouth in the English Channel in around $50 \mathrm{~m}$ of water. The L4 site is situated in the river Tamar outflow region. Weekly chlorophyll and nutrient (nitrate, phosphate, and silicate) data was used in this study. Details of the data and sampling protocols are available at the observatory website (www.westernchannelobservatory.org.uk).

Comparisons were made between satellite-derived and model surface chlorophyll (and log chlorophyll) for the AMM7-NE and MRCS-PE systems with averages over different time periods (daily, monthly, and seasonal). The satellite-derived chlorophyll data was calculated using the OC5 algorithm for Case II coastal waters (Gohin et al., 2002, 2005) by IFREMER and delivered through MyOcean (www. myocean.eu). The daily comparison between the model and satellite chlorophyll fields was made for the total domain and a series of sub-domains on the shelf (Fig. 2). These subdomains also include the on-shelf region or Actual North West Shelf (Fig. 8). The on-shelf region was defined to fit the MRCS model grid and roughly follows the $200 \mathrm{~m}$ isobath. For the monthly and seasonal comparisons, the daily satellite-derived chlorophyll data was first (bilinear) interpolated onto the model grid and then averaged as appropriate.

\subsection{Skill assessment}

The main statistics used to assess the results in this paper, as recommended by Allen et al. (2007), are mean error (or bias $=$ observations minus model), the root mean square error (RMSE), normalised standard deviation $\left(s_{\mathrm{n}}\right.$; the ratio of the model standard deviation to the observed standard deviation) and Pearson's correlation coefficient $(r)$. The bias and RMSE measure the discrepancy between modelled and observed values where values closer to zero indicate a closer match. The correlation provides a measure of linear correspondence between two variables and values can range from -1 to +1 . A value of +1 implies that a linear equation defines the relationship between the two variables while a value of -1 still indicates that the data points also fit a linear equation but with negative slope. A value of zero indicates no linear relationship. The square of the correlation coefficient $\left(r^{2}\right)$ is an estimate of the fraction of the variance accounted for.

The RMSE, correlation and normalised standard deviation (model standard deviation divided by observation standard deviation) can be summarised on a single diagram, a Taylor plot (Taylor, 2001). The use of Taylor plots for coupled hydrodynamic-ecosystem models is well described in Jolliff et al. (2009). A perfect match between model and observations would plot at the reference point labelled 1.0 on the $\mathrm{x}$-axis.

Additionally, we have included the percentage model bias (Pbias) which is the sum of model error normalised by the data (Allen et al., 2007) and the cost function $(\chi)$ from Holt et al. (2005):

$\chi^{2}=\frac{1}{n \sigma_{\mathrm{o}}^{2}} \sum\left(D_{\mathrm{n}}-M_{\mathrm{n}}\right)^{2}$.

Where $D$ and $M$ represent the data and corresponding model estimate; $n$ is the number of observations and $\sigma_{\mathrm{o}}$ is the standard deviation of the data. $\chi^{2}$ is related to the model efficiency (ME) recommended by Allen et al. (2007) as: $\mathrm{ME}=1-\chi^{2}$. According to Holt et al. (2005) a value of $\chi<$ 1.0 is required if the model is to have predictive skill while a "well modelled" variable would have $\chi<0.4$. Allen et 


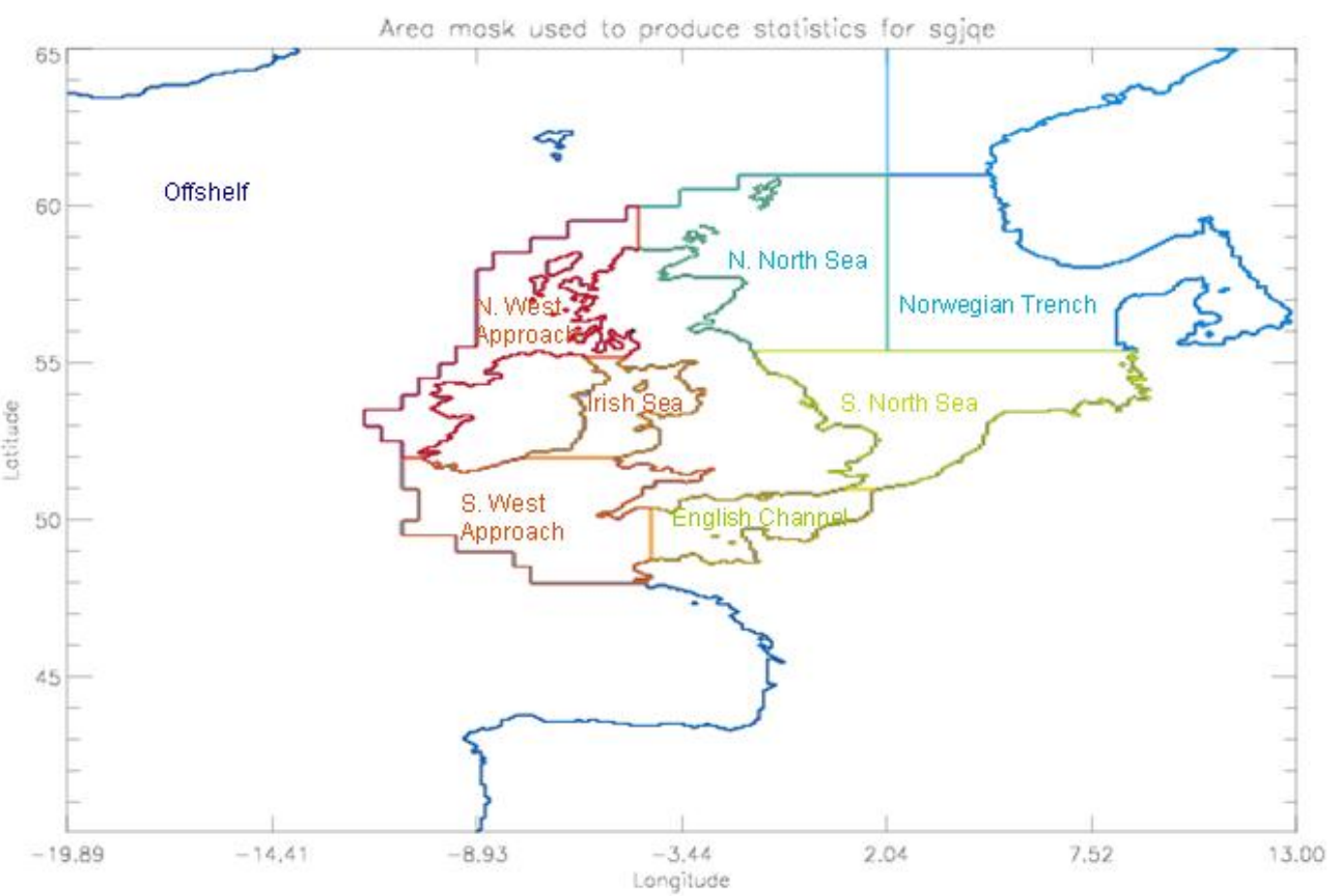

Fig. 2. Area mask used to produce the Taylor plot and some statistics. The on-shelf region used in the text includes all of the other regions except off-shelf.
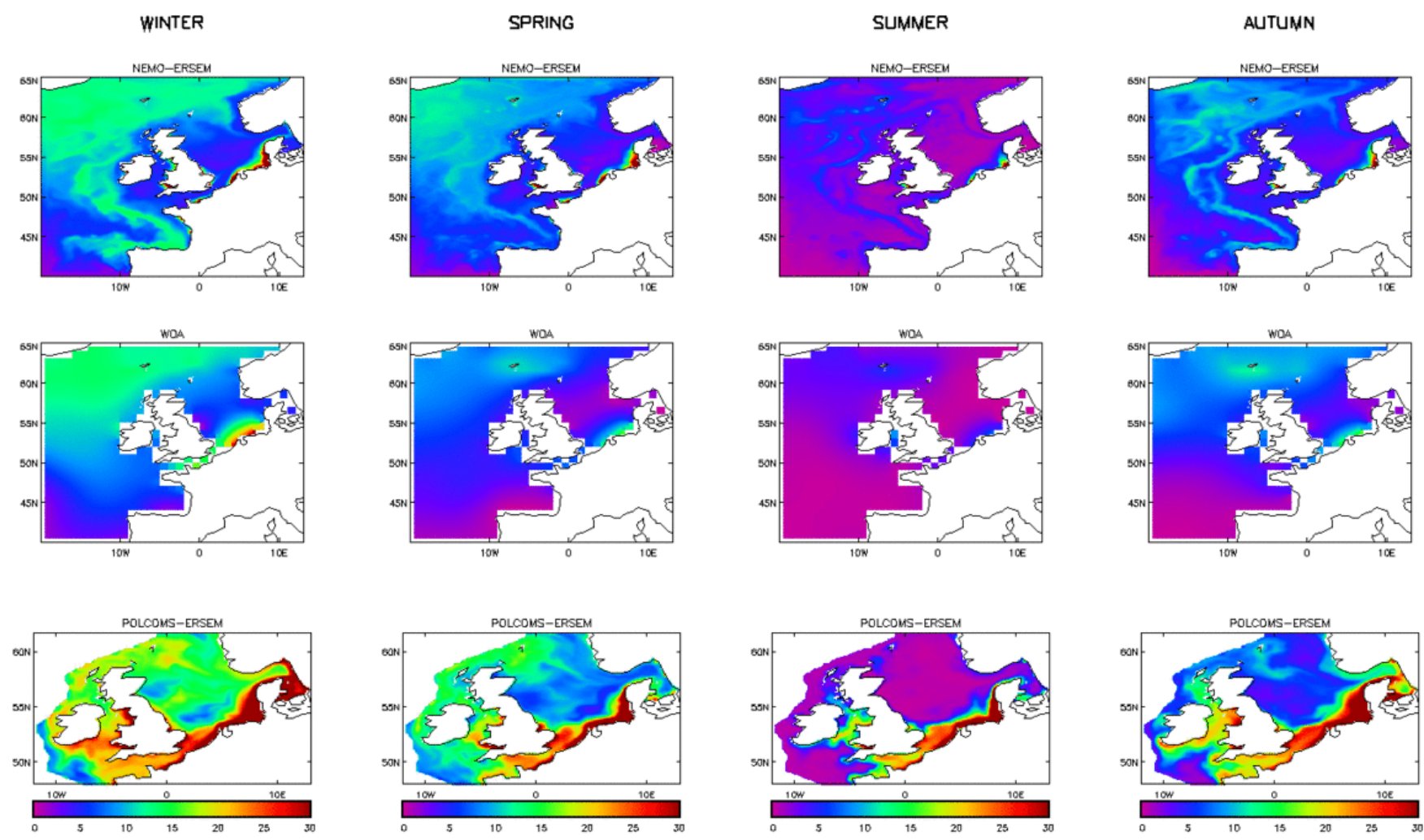

Fig. 3. Seasonal averages of nitrate values $\left(\mathrm{mmol} \mathrm{m}^{-3}\right)$ for AMM7-NE (top row) compared to the WOA09 fields (middle row) and MRCSPE (bottom row). The MRCS-PE and AMM7-NE fields are for 2008. Winter = December 2007-February 2008; Spring = March, April and May 2008; Summer = June, July and August 2008; Autumn = September, October and November 2008. 

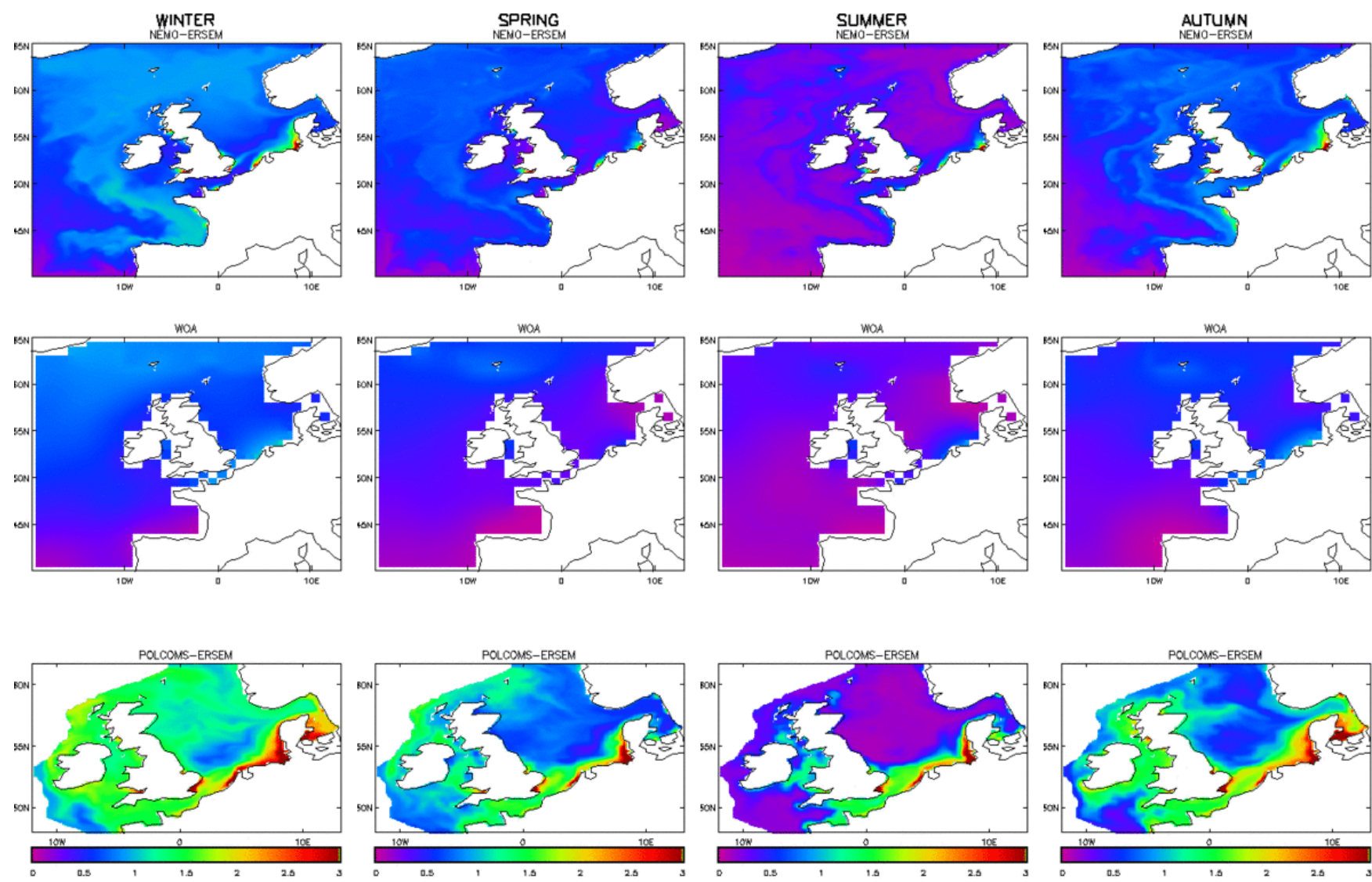

Fig. 4. As in Fig. 3, the seasonal average surface phosphate $\left(\mathrm{mmol} \mathrm{m}^{-3}\right)$ for 2008 for AMM7-NE (top) and MRCS-PE (bottom) compared with the WOA09 climatology (centre).

al. (2007) performance levels of $|\mathrm{Pbias}|$ as $<10 \%$ excellent, $10 \%-20 \%$ very good, $20 \%-40 \%$ good, and $>40 \%$ poor.

\section{Results}

\subsection{Nutrient assessment}

Comparisons were made between the World Ocean Atlas 2009 nutrient climatology (Garcia et al., 2010) and the AMM7-NE and MRCS-PE results for monthly and seasonal averages. Seasonal averages of 2008 nitrate values for MRCS-PE (top) and AMM7-NE (bottom) are provided in Fig. 3 along with the WOA09 climatological values (centre), while the combined 2007-2008 statistics (created from the averaged fields) are provided in Table 1. For comparison to the MRCS-PE, the statistics for AMM7-NE are provided for both the entire domain and just the MRCS domain. The improvement in the nitrate field in the AMM7-NE model is evident when comparing both the cost function $(\chi)$ and Pbias. The cost function for nitrate on both the AMM7 and MRCS domain is $<1.0$ indicating some predictive skill in the model as compared with MRCS-PE system of $>2.0$. On the MRCS domain, the AMM7-NE model has $|\mathrm{Pbias}|<10 \%$ in- dicating excellent performance of the model. Additionally, on the MRCS domain the AMM7-NE system has much lower RMSE ( $3.455 \mathrm{mmol} \mathrm{NO}_{3} \mathrm{~m}^{-3}$ versus $9.124 \mathrm{mmol} \mathrm{NO}_{3} \mathrm{~m}^{-3}$ ) based on monthly averages. The AMM7-NE statistics over the entire AMM7 domain are also quite good with lower RMSE values and higher correlations which are above 0.600 for both the monthly and seasonal averages.

A similar analysis has been completed for the phosphate and silicate fields in ERSEM as compared with WOA09 with the results shown in Table 1 and Figs. 4 (phosphate) and 5 (silicate). The phosphate results show marked improvement over the MRCS-PE values with lower RMSE values $\left(0.303 \mathrm{mmol} \mathrm{m}^{-3}\right.$ versus $\left.0.616 \mathrm{mmol} \mathrm{m}^{-3}\right)$ and |Pbiases| (28\% versus $97.9 \%$ ) on the MRCS domain. The cost function $(\chi)$ is $>1.0$ for both the AMM7-NE system and MRCSPE system but is still much lower (about half) for the AMM7NE system on both the entire domain and the MRCS region. While the AMM7-NE correlation on the MRCS domain is lower than the MRCS-PE system, the correlation over the entire domain for each model is similar, while the RMSE values and biases show improvement in the AMM7-NE system.

The statistics for the AMM7-NE silicate field (on both the full domain and the MRCS sub-domain) are not as 
Table 1. Statistics for monthly-mean and seasonal-mean values of nitrate, phosphate and silicate for AMM7-NE and MRCS-PE versus WOA09 climatology values on the model domains. The first two columns include the entire AMM7 domain, while the two middle columns provide the statistics from the AMM7-NE model on the MRCS sub-domain only. The units for the RMSE and Bias are mmol $\mathrm{m}^{-3}$.

\begin{tabular}{|c|c|c|c|c|c|c|}
\hline & \multicolumn{2}{|c|}{ AMM7-NE } & \multicolumn{2}{|c|}{ AMM7-NE-MRCS } & \multicolumn{2}{|c|}{ MRCS-PE } \\
\hline & Monthly & Seasonal & Monthly & Seasonal & Monthly & Seasonal \\
\hline \multicolumn{7}{|l|}{ 1. Nitrate } \\
\hline Correlation & 0.604 & 0.642 & 0.420 & 0.440 & 0.521 & 0.553 \\
\hline RMSE & 3.012 & 2.722 & 3.455 & 3.246 & 9.124 & 8.652 \\
\hline$s_{\mathrm{n}}$ & 1.222 & 1.248 & 1.500 & 1.593 & 2.680 & 2.785 \\
\hline Bias & -1.058 & -1.087 & 0.153 & 0.170 & -5.251 & -5.106 \\
\hline Pbias & $-20.7 \%$ & $-21.3 \%$ & $2.7 \%$ & $3.0 \%$ & $-93.6 \%$ & $-91 \%$ \\
\hline$\chi$ & 0.7 & 0.682 & 0.791 & 0.817 & 2.084 & 2.174 \\
\hline \multicolumn{7}{|l|}{ 2. Phosphate } \\
\hline Correlation & 0.476 & 0.534 & 0.288 & 0.322 & 0.470 & 0.532 \\
\hline RMSE & 0.261 & 0.228 & 0.303 & 0.265 & 0.616 & 0.570 \\
\hline$s_{\mathrm{n}}$ & 1.339 & 1.311 & 1.650 & 2.732 & 3.040 & 4.973 \\
\hline Bias & -0.126 & -0.125 & -0.124 & -0.117 & -0.434 & -0.413 \\
\hline Pbias & $-32.4 \%$ & $-32.1 \%$ & $-28.0 \%$ & $-26.4 \%$ & $-97.9 \%$ & $-93.1 \%$ \\
\hline$\chi$ & 1.101 & 1.040 & 1.390 & 2.211 & 2.826 & 4.764 \\
\hline \multicolumn{7}{|l|}{ 3. Silicate } \\
\hline Correlation & 0.244 & 0.280 & 0.219 & 0.212 & 0.563 & 0.613 \\
\hline RMSE & 2.776 & 2.391 & 2.765 & 2.314 & 3.741 & 3.444 \\
\hline$s_{\mathrm{n}}$ & 1.777 & 1.763 & 1.864 & 1.815 & 3.136 & 3.167 \\
\hline Bias & -0.698 & -0.695 & -0.207 & -0.111 & -0.753 & -0.723 \\
\hline Pbias & $-27.2 \%$ & $-27.1 \%$ & $-7.2 \%$ & $-3.9 \%$ & $-25.6 \%$ & $-24.6 \%$ \\
\hline$\chi$ & 1.399 & 1.342 & 1.265 & 1.153 & 1.712 & 1.710 \\
\hline
\end{tabular}

Table 2. Statistics for values of nitrate, phosphate, silicate and $\log$ Chl for (1) AMM7-NE and (2) MRCS-PE versus L4 in situ values. The units for the RMSE and Bias are $\mathrm{mmol} \mathrm{m}^{-3}$.

\begin{tabular}{|c|c|c|c|c|}
\hline & Nitrate & Phosphate & Silicate & $\log _{10}(\mathrm{Chl})$ \\
\hline \multicolumn{5}{|c|}{ 1. AMM7-NE } \\
\hline Correlation & 0.843 & 0.656 & 0.702 & 0.254 \\
\hline RMSE & 1.651 & 0.222 & 1.689 & 0.463 \\
\hline$s_{\mathrm{n}}$ & 0.709 & 1.016 & 1.125 & 1.314 \\
\hline Bias & -0.261 & -0.152 & 0.426 & 0.023 \\
\hline Pbias & $-9.0 \%$ & $-68.1 \%$ & $16.9 \%$ & $42.9 \%$ \\
\hline$\chi$ & 0.561 & 1.152 & 0.848 & 1.400 \\
\hline \multicolumn{5}{|c|}{ 2. MRCS-PE } \\
\hline Correlation & 0.747 & 0.689 & 0.801 & 0.282 \\
\hline RMSE & 12.029 & 0.875 & 5.998 & 0.671 \\
\hline$s_{\mathrm{n}}$ & 2.555 & 2.585 & 3.049 & 1.970 \\
\hline Bias & -10.498 & -0.773 & -3.877 & -0.257 \\
\hline Pbias & $-362 \%$ & $-346 \%$ & $-154 \%$ & $-478 \%$ \\
\hline$\chi$ & 4.092 & 4.539 & 3.011 & 2.028 \\
\hline
\end{tabular}

good as for the nitrate and phosphate, with lower correlations $(0.244$ and 0.280 for silicate versus 0.476 and 0.534 for phosphate on the AMM7 domain) for both the monthly and seasonal averages along with relatively higher RMS errors $\left(2.776 \mathrm{mmol} \mathrm{m}^{-3}\right.$ and $2.391 \mathrm{mmol} \mathrm{m}^{-3}$ for silicate and $0.261 \mathrm{mmol} \mathrm{m}^{-3}$ and $0.228 \mathrm{mmol} \mathrm{m}^{-3}$ for phosphate), the improvement in silicate from the MRCS-PE system is evident. While the cost function $(\chi)$ is greater than 1.0 for all of the silicate averaging schemes presented in Table 1, it is still lower for the AMM7-NE system than for the MRCS-PE system. As compared to the MRCS-PE, the Pbias on the MRCS domain for the AMM7-NE system is significantly reduced $(<10 \%$ compared with $>90 \%)$. The |Pbias $\mid$ for the entire AMM7-NE domain is still quite good at approximately $20 \%$ for both the seasonal and monthly averages. From Fig. 5, it is also apparent that the main source of excess silicate in the AMM7-NE system is in the Bay of Biscay and northward along the shelf-break to the west of Ireland. This may be partially caused by excess upwelling in the NEMO model along the steep slopes in these regions (John Siddorn, personal communication) through spurious diapycnal mixing and is also evident, but to a lesser extent, in the other ERSEM variables (see Figs. 2, 3 and 9). There is certainly too much diapycnal mixing in the physical model which may be made worse in ERSEM through the use of the MUSCL advection scheme. The MUSCL scheme is very diffusive but provided 

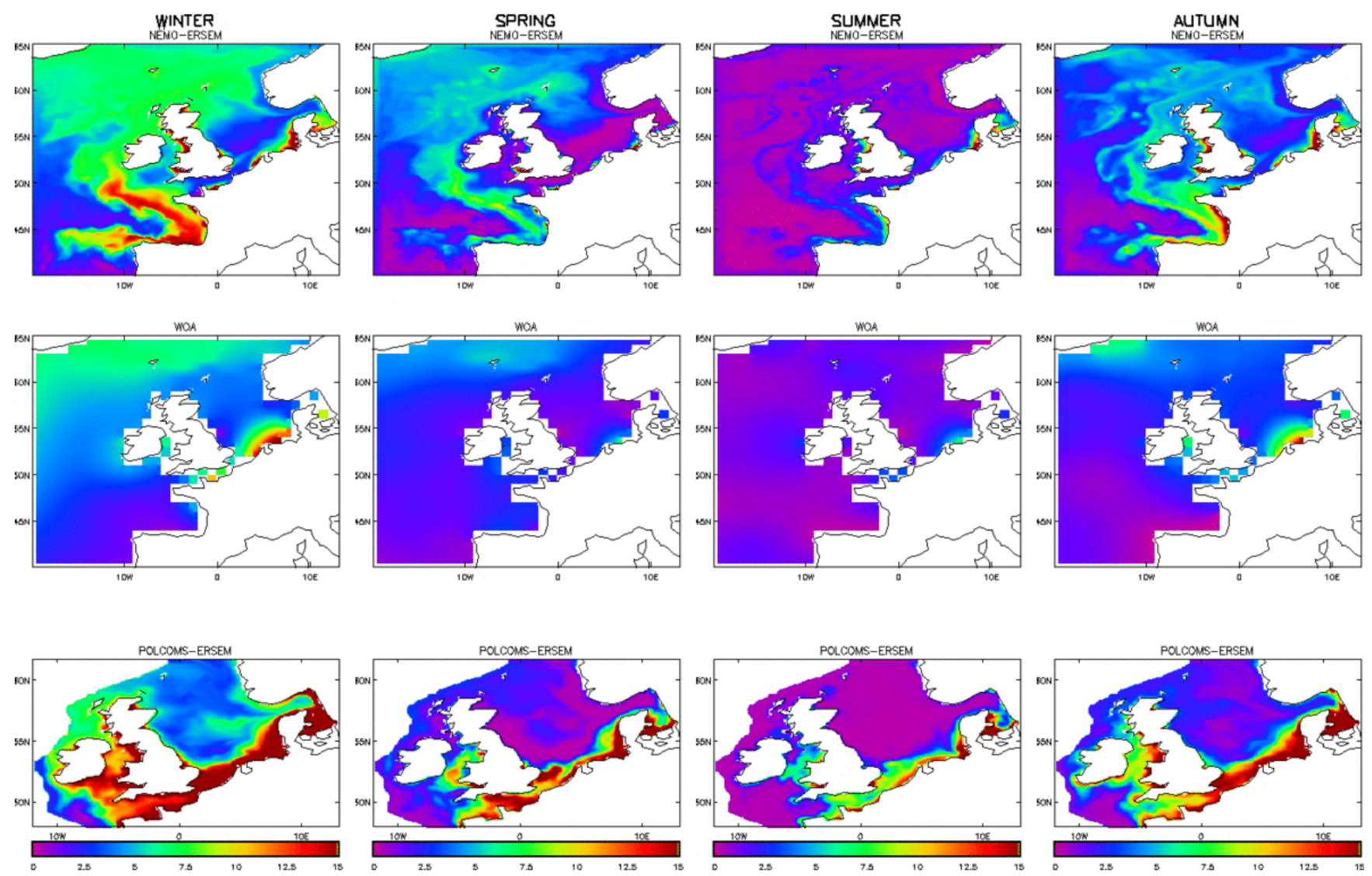

Fig. 5. As in Fig. 3, seasonal average surface silicate $\left(\mathrm{mmol} \mathrm{m}^{-3}\right)$ for 2008 for AMM7-NE (top) and MRCS-PE (bottom) compared with the WOA09 climatology (centre).

necessary stability; work investigating alternative advection schemes is ongoing. There is some discussion of the problems with the physics along with corrections that were made to help minimise these problems in O'Dea et al. (2012). Further work is being undertaken to improve the model results along the shelf break.

Figure 6 provides a time series comparison between the model results and in situ data at the L4 buoy with statistics provided in Table 2. The AMM7-NE model nutrient values follow the in situ observations very well and generally match the observed seasonal pattern, although the silicate drawdown in the model occurs earlier in each calendar year than in the observations. The cost functions $(\chi)$ for the AMM7NE system are generally better than for the MRCS-PE model with values of $<1.0$ for nitrate and silicate and values $<1.5$ for phosphate and $\log _{10}$ (chlorophyll). The cost functions for the MRCS-PE system are all $>2.0$ with the values for nitrate and phosphate $>4.0$. The nutrient correlation values are quite high: with nitrate equal to 0.835 , phosphate equal to 0.678 and silicate equal to 0.665 . The AMM7-NE model $\log _{10}$ (chlorophyll) provides a good match to the observations with a $|\mathrm{Pbias}|$ of approximately $40 \%$ but a correlation of only 0.254 . From Fig. 6, the MRCS-PE model nutrients are too high resulting in high chlorophyll values throughout most of the year (a |Pbias| of $478 \%$ ).

Finally, although the in situ data are very sparse for 2007 and 2008, a comparison (not shown) has been made between the model results and the Cefas SmartBuoy nitrate and silicate data. The cost functions $(\chi)$ for both nitrate and silicate are good for three of the four SmartBuoy sites (Oyster Grounds, Liverpool Bay and Gabbard) with values either less than or close to 1.0 for nitrate and between 1.5 to around 2.0 for silicate. The best overall fit between the AMM7-NE model results and SmartBuoy data is at the Oyster Grounds with a cost function of 0.893 for nitrate and 1.428 for silicate and correlations of around 0.57 for both. The AMM7-NE statistics for nitrate are very good $\left(\mathrm{RMSE}=1.37 \mathrm{mmol} \mathrm{m}^{-3}\right.$; Pbias $\left.=+24 \%\right)$ but are not as good for silicate $\left(\mathrm{RMSE}=2.41 \mathrm{mmol} \mathrm{m}^{-3}\right.$; Pbias $\left.=+73 \%\right)$. The positive Pbias values indicate that the AMM7-NE model underestimates the nutrient values at this location. Although the AMM7-NE nitrate correlation is quite high at Warp Anchorage (0.818), indicating that the pattern of nitrate concentration is good, the remaining statistics at Warp Anchorage are poor (with an RMSE of approximately $50 \mathrm{mmol} \mathrm{m}^{-3}$ for both nitrate and silicate and a nitrate cost function of almost 

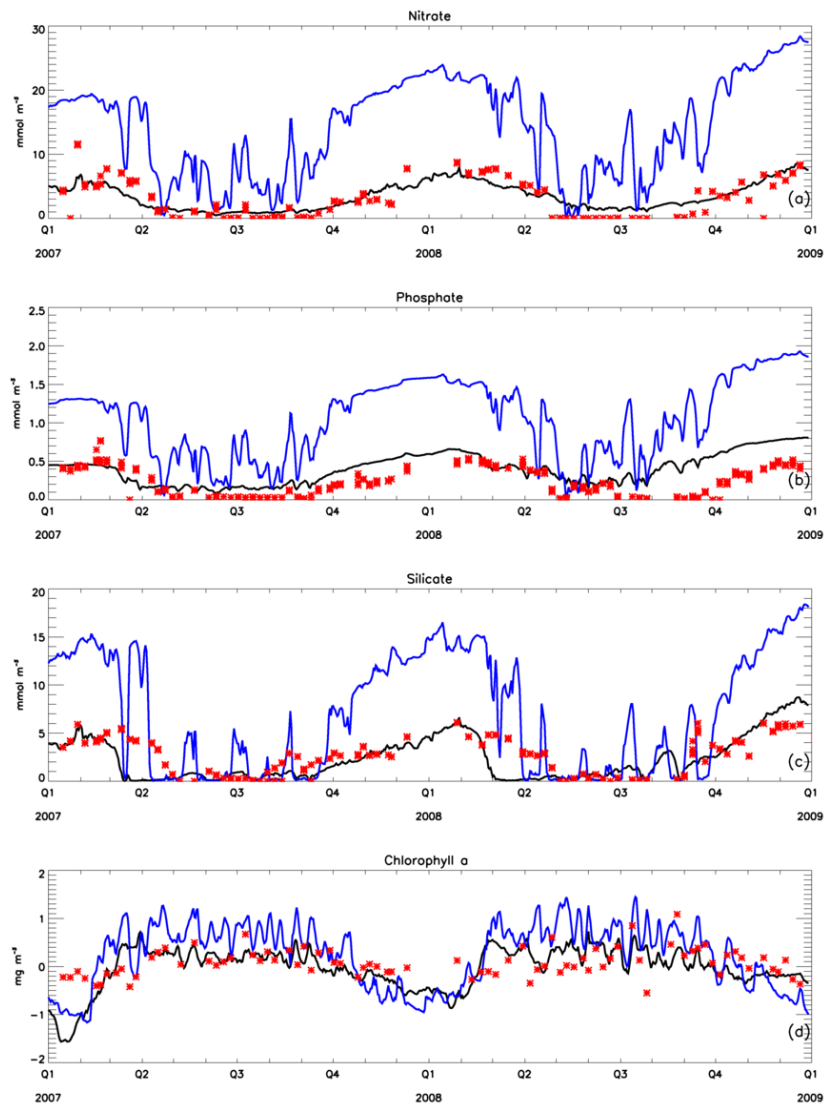

Fig. 6. Comparison of AMM7-NE (black), MRCS-PE (blue) and in situ data (red) at the L4 buoy: (a) nitrate, (b) phosphate, (c) silicate and (d) $\log _{10}$ (chlorophyll).

5.0) and the model nutrients are very high (almost double the in situ observations in the winter). This is probably due to the fact that the Warp Anchorage SmartBuoy is located at the first water point adjacent to the land in the AMM7-NE domain; the model does not resolve very small, fine scale processes in the estuary. This is also one of the river input points for the model so nutrients and sediment are constantly being added into the domain at this point. At all locations, it is appears that the silicate in the model is drawn-down too early in the spring with respect to the observations in a similar pattern to that seen at L4 (Fig. 6).

\subsection{Chlorophyll assessment}

A summary of the on-shelf statistics for the entire 2-year hindcast period is presented in Table 3. In general, the statistics for the AMM7-NE system are improved relative to the MRCS-PE system with slightly higher correlations $(0.294$ versus 0.255$)$ and similar RMS errors $\left(0.645 \log _{10}\left(\mathrm{mg} \mathrm{m}^{-3}\right)\right.$ versus $\left.0.613 \log _{10}\left(\mathrm{mg} \mathrm{m}^{-3}\right)\right)$. Of note is the reduction in mean error (or bias) and percentage bias for the two-year hindcast period. The AMM7-NE |Pbias| is $16.4 \%$ - indicating that the total chlorophyll in the MRCS region is approxi-
Table 3. Summary of daily surface $\log _{10}$ (chlorophyll) statistics calculated on the on-shelf region (Fig. 2) for both AMM7-NE and MRCS-PE for the 2-year hindcast. The units for the RMSE and Bias are $\log _{10}\left(\mathrm{mg} \mathrm{m}^{-3}\right)$.

\begin{tabular}{lrr}
\hline & AMM7-NE & MRCS-PE \\
\hline Correlation & 0.294 & 0.255 \\
RMSE & 0.645 & 0.613 \\
$S_{\mathrm{n}}$ & 1.985 & 1.652 \\
Bias & 0.009 & -0.209 \\
Pbias & $16.4 \%$ & $-475.0 \%$ \\
$\chi$ & 1.943 & 1.808 \\
\hline
\end{tabular}

mately of the correct magnitude on average; while the negative bias and large |Pbias| of $475 \%$ for the MRCS-PE system indicates that the model has too much chlorophyll relative to observations. However, the relatively high RMS errors indicate that the timing and pattern of the model chlorophyll is not entirely correct. The cost functions for both the AMM7NE and MRCS-PE are similar and close to 2.0.

A time series of the daily mean and RMS errors of surface $\log _{10}$ (chlorophyll) for the on-shelf region of the MRCS-PE and AMM7-NE systems is provided in Fig. 7. In the winter, when the bias is positive for both model systems, the model chlorophyll is too low relative to the observations. This is reversed in the spring and summer, when the bias is negative indicating that the model chlorophyll is higher than the observations. From this figure, it is also apparent that at certain times of year (most obviously April through October), the AMM7-NE system has a lower RMS error (solid line) and bias (dotted line) than the MRCS-PE system but during the first two winter periods, the AMM7-NE errors are much more variable and higher than the MRCS-PE. However, by the end of the hindcast period and the third winter season of the run, the AMM7-NE model errors on the shelf are comparable to MRCS-PE (Fig. 7). This may indicate that the AMM7-NE model needed more time to synchronise from the initial conditions interpolated from the AMM12 POLCOMSERSEM model to AMM7-NE or that the sediment model needed more than one year to spin-up. Calculating the statistics separately for 2007 and 2008 for the AMM7-NE on-shelf region results in correlations which are essentially the same (0.303 for 2008 versus 0.301 for 2007) along with a slight reduction in RMSE $\left(0.637 \log _{10}\left(\mathrm{mg} \mathrm{m}^{-3}\right)\right.$ versus $0.654 \log _{10}$ $\left.\left(\mathrm{mg} \mathrm{m}^{-3}\right)\right)$. In the on-shelf region for AMM7-NE, the bias in chlorophyll is close to zero for both years, but reverses sign from $+0.082 \log _{10}\left(\mathrm{mg} \mathrm{m}^{-3}\right)$ in 2007 , indicating slightly too little chlorophyll, to $-0.060 \log _{10}\left(\mathrm{mg} \mathrm{m}^{-3}\right)$, indicating slightly too much chlorophyll in 2008.

Taylor plots are used in Fig. 8 to compare the two model systems over the entire domain as well as the predefined sub-domains and show some specific areas where the AMM7-NE system clearly outperforms MRCS-PE with respect to surface $\log _{10}$ (chlorophyll) concentrations. The areas 


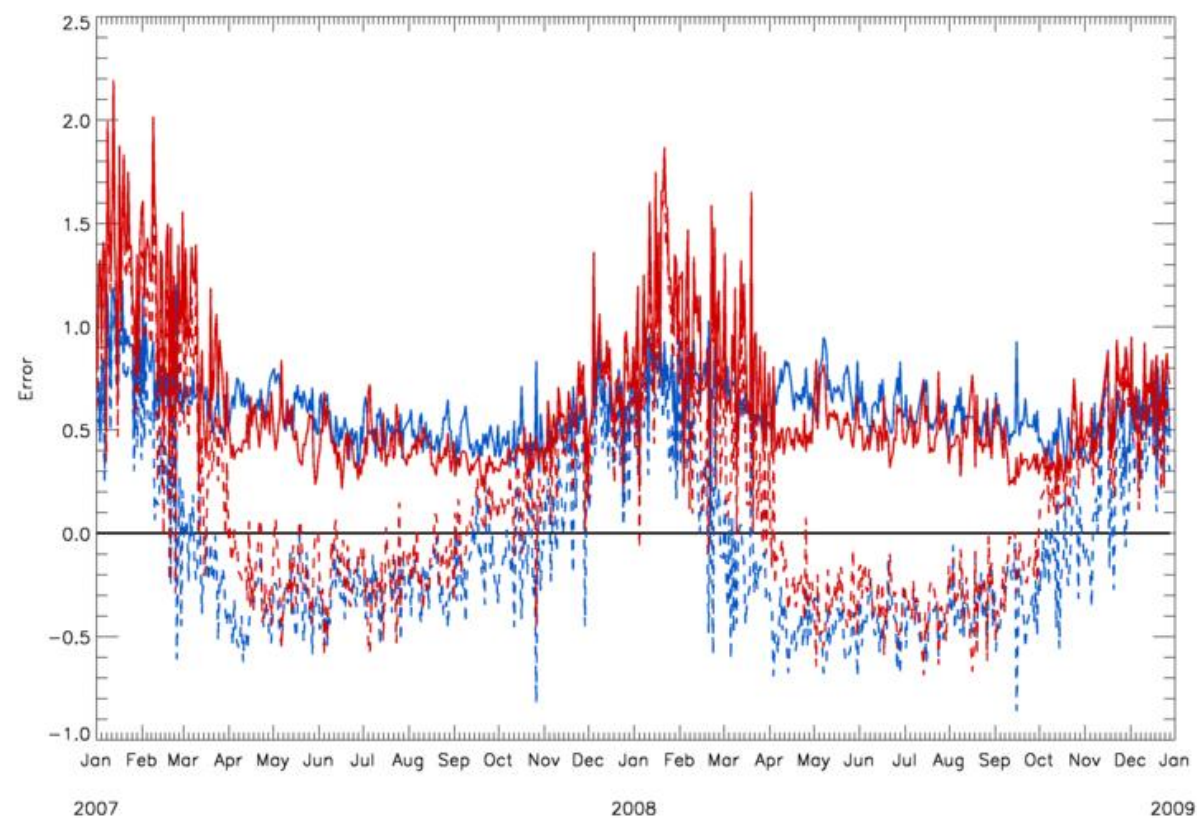

Fig. 7. Comparison of error estimates for $\log _{10}$ (chlorophyll) in the on-shelf region (Fig. 2) for MRCS-PE (blue) and AMM7-NE (red). Solid lines $=$ RMSE; dashed lines $=$ bias (obs-model).

Taylor Diagram of $\log 10$ (Chlorophyll concentration)

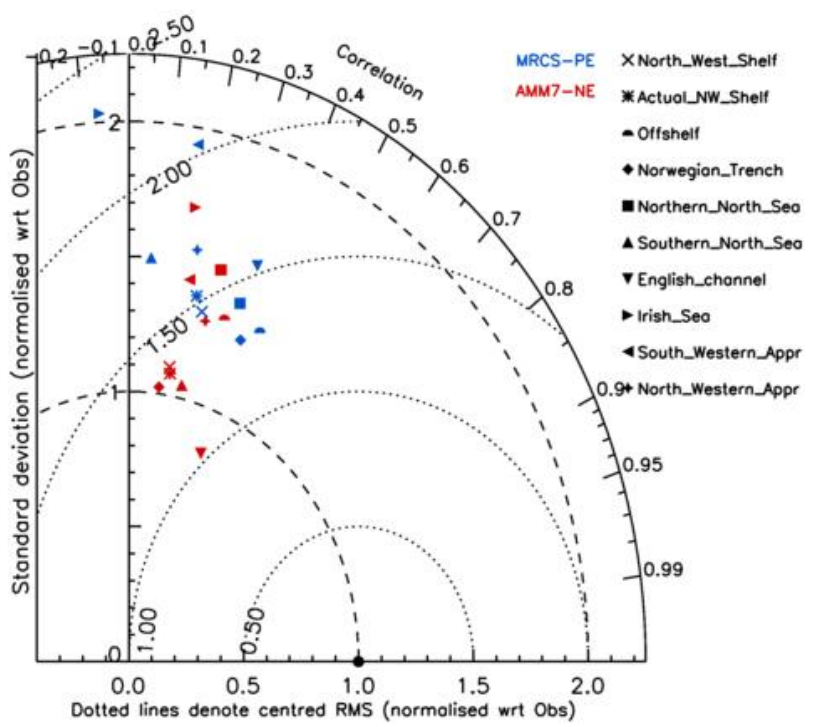

Fig. 8. Taylor plot to compare MRCS-PE (blue) and AMM7-NE (red) surface chlorophyll with satellite-derived chlorophyll. The areas are shown in Fig. 2 and North_West_Shelf represents the entire AMM7 domain.

with the most improvement include the Irish Sea, English Channel, Norwegian Trench and southern North Sea as defined in Fig. 2. In this plot, the Norwegian Trench and southern North Sea data for AMM7-NE sit very close to the curved dashed line running between 1.0 on both the $\mathrm{x}$ - and $\mathrm{y}$-axes. This line represents a perfect match of the model and obser- vation standard deviations (for the Taylor plot only, a minimum model value of $0.1 \mathrm{mg}$ chlorophyll $\mathrm{m}^{-3}$ was used to match the minimum value provided by the satellite data). The Irish Sea area also had a negative correlation in the MRCSPE model which has been improved in AMM7-NE. The correlation, obtained by drawing a line from the origin through a plotted point to the curved right-axis, is generally low for most regions with the English Channel having the highest correlation of 0.366 . This region also has the lowest cost function of 1.046 and a very low Pbias of $-2.9 \%$ and RMS error of $0.293 \log _{10}\left(\mathrm{mg} \mathrm{m}^{-3}\right)$.

The statistics presented in Table 3 and Fig. 7, are based on a daily comparison of the model versus satellite values which may be overly strict as the errors in both can be high. Averaging over weeks, months or seasons before comparing the model results to the satellite data improves the correlations in AMM7-NE $\log _{10}$ (chlorophyll) to $0.383,0.455$ and 0.415 , respectively with relatively small changes to the RMS error or bias or cost functions. A similar pattern in these statistics is seen with higher, positive biases in the winter months (October through March) and lower, slightly negative biases in the remainder of the year. Figure 9 shows the seasonal averages of the satellite observations compared to the AMM7-NE model results for chlorophyll on a log scale. The spatial and temporal differences become readily apparent in this figure: the spatial pattern of chlorophyll in winter looks quite reasonable although the model values are generally lower than the satellite observations, while in spring and summer, the model has too much chlorophyll relative to the observations 
WINTER
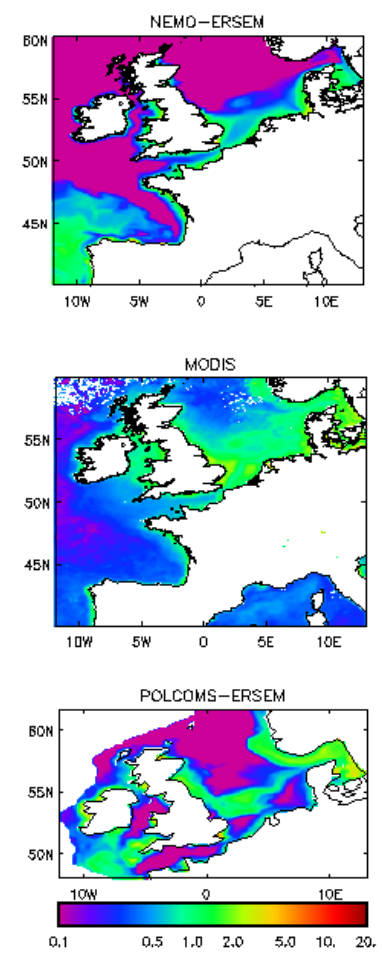

SPRING
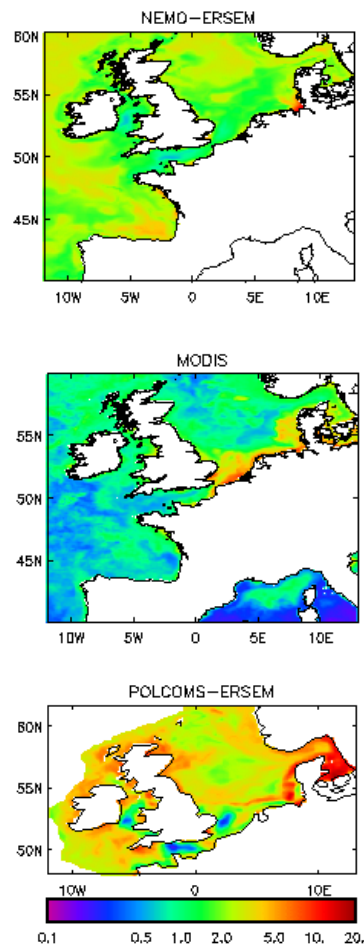

SUMNER
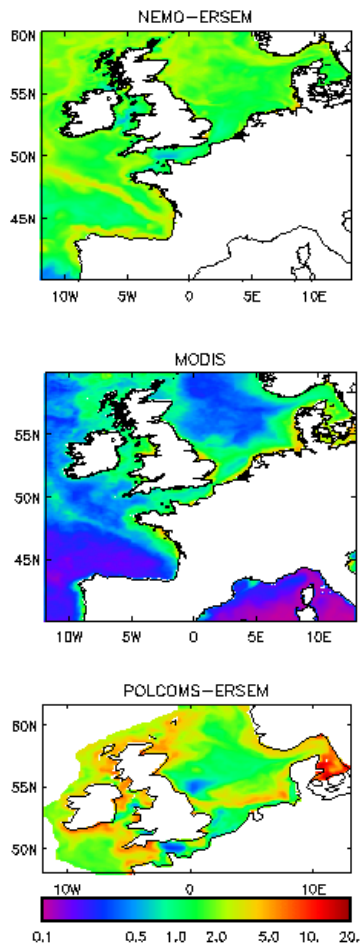

AUTUNN
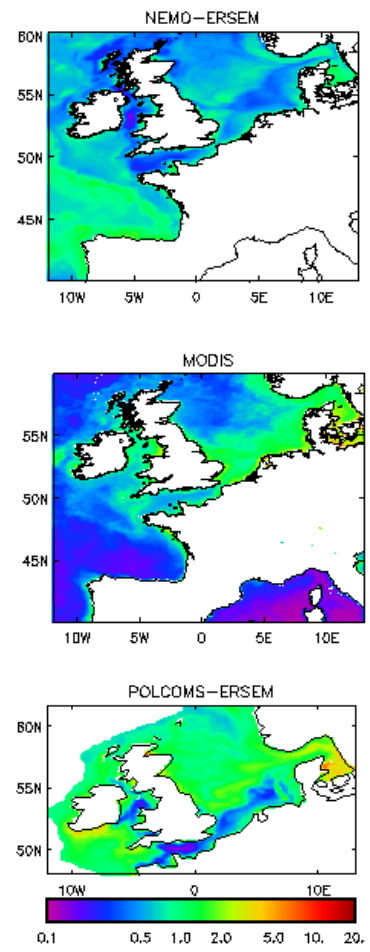

Fig. 9. As in Fig. 3. Seasonal average surface $\log _{10}$ (chlorophyll) for AMM7-NE (top) and MRCS-PE (bottom) as compared to the satellitederived chlorophyll (middle).

which is widely distributed through the domain (except very near the coast).

The final comparison for the model chlorophyll is provided at four of the Cefas SmartBuoy sites. Figure 10 provides a comparison of model, satellite and SmartBuoy $\log _{10}$ (chlorophyll) data at the West Gabbard location. At this location, the cost functions between the model and in situ data are the best at 0.995 . The correlation between satellite and SmartBuoy in situ data is 0.600 , while the correlation between the model and satellite is 0.190 and the model and in situ data is 0.310 . In the time series plot provided by Fig. 10d, it is apparent that while several of the peaks in $\log _{10}$ (chlorophyll) values match in both the satellite and SmartBuoy time series, the SmartBuoy data has several other peaks which may or may not be realistic, but also, the satellite data does not have correspondingly low values where both the in situ and model values are low. Tables 4 and 5 present the statistics for all of the SmartBuoy locations. Table 4 includes both the model and satellite statistics versus the SmartBuoy in situ data while Table 5 has the model versus satellite statistics at the SmartBuoy location. The Oyster Banks SmartBuoy is located much further from the coast than the other three, so it is surprising that the statistics at this location are worse (from Table 4, lowest and negative correlations, highest RMSE and bias) than at the coastal locations for both the AMM7-NE model and satellite data as compared to the in situ data. However, it is not surprising that the AMM7-NE model does not do very well at the coastal locations when compared with observations. One of the limitations in our current system is the use of climatological values as input for the rivers; this will naturally mean that the model misses large freshwater inputs as they will be smoothed in the climatological input.

\section{Discussion}

This paper describes updates made to the Met Office's operational coupled hydrodynamic-ecosystem model for the European NWS to the AMM7-NE system. As stated above, the new AMM7-NE system has emerged from previous systems on the North West European Continental Shelf (including the MRCS-PE system as described by Siddorn et al., 2007). Ongoing validation of intermediate results on the related POLCOMS-AMM configuration (Holt et al., 2012; Butenschön et al., 2012) has been carried out through projects such as MEECE (http://www.meece.eu/). However, this paper provides validation of some of the ecosystem variables in an operational context including chlorophyll and the main nutrients: nitrate, phosphate, and silicate. This new system is now part of the daily operational suite at the Met Office and 

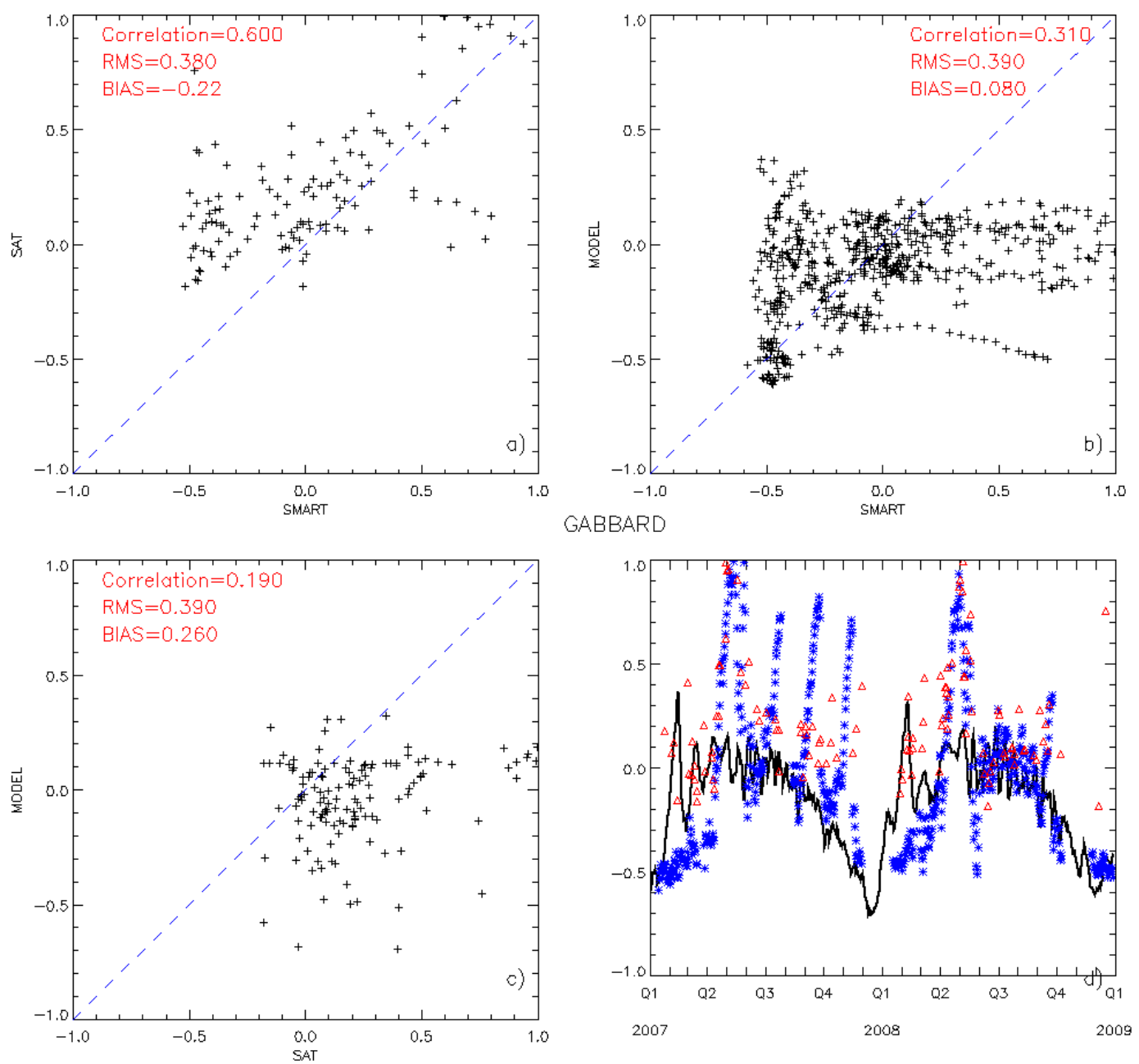

Fig. 10. Plots and statistics of $\log _{10}$ (chlorophyll) at the Gabbard SmartBuoy: (a) SmartBuoy versus Satellite; (b) SmartBuoy versus Model; (c) Satellite versus Model; and (d) time series of model (black), SmartBuoy (blue) and satellite (red).

Table 4. Surface daily $\log _{10}$ (chlorophyll) statistics of AMM7-NE model and satellite values versus in situ data at the Cefas SmartBuoy locations. The units for the RMSE and Bias are $\log _{10}\left(\mathrm{mg} \mathrm{m}^{-3}\right)$.

\begin{tabular}{|c|c|c|c|c|c|c|c|c|}
\hline & \multicolumn{2}{|c|}{ Gabbard } & \multicolumn{2}{|c|}{ Liverpool Bay } & \multicolumn{2}{|c|}{ Oyster Banks } & \multicolumn{2}{|c|}{ Warp } \\
\hline & sat & model & sat & model & sat & model & sat & model \\
\hline Correlation & 0.600 & 0.310 & 0.490 & 0.050 & 0.080 & -0.180 & 0.490 & -0.100 \\
\hline RMSE & 0.380 & 0.390 & 0.590 & 0.610 & 0.740 & 0.920 & 0.650 & 0.870 \\
\hline$s_{\mathrm{n}}$ & 0.661 & 0.582 & 0.426 & 0.556 & 0.310 & 0.759 & 0.459 & 0.612 \\
\hline Bias & -0.220 & 0.080 & -0.400 & -0.190 & 0.300 & 0.390 & -0.190 & -0.220 \\
\hline Pbias & $1100 \%$ & $400 \%$ & $932 \%$ & $442 \%$ & $180 \%$ & $234 \%$ & $-113 \%$ & $-134 \%$ \\
\hline$\chi$ & 0.965 & 0.995 & 1.146 & 1.187 & 1.210 & 1.501 & 0.946 & 1.259 \\
\hline
\end{tabular}

has been providing 5-day forecasts with improved products delivered through MyOcean (www.myocean.eu.org) since March 2012.

The results show that the AMM7-NE system shows significant skill and performs better compared to the previous MRCS-PE system especially for the nutrient fields. Many of the cost functions $(\chi)$ for the nutrients in the AMM7$\mathrm{NE}$ system are $<1.0$ indicating some predictive skill in the model. Additionally, even the cost functions which are not $<1.0$ are generally still closer to 1.0 for the AMM7-NE system than for the MRCS-PE system (see Tables 1 and 2 along with the text) indicating a substantial improvement. For the 
Table 5. Surface daily $\log _{10}$ (chlorophyll) statistics for AMM7-NE model versus satellite data at the Cefas SmartBuoy locations. The units for the RMSE and Bias are $\log _{10}\left(\mathrm{mg} \mathrm{m}^{-3}\right)$.

\begin{tabular}{lrrrr}
\hline & Gabbard & Liverpool Bay & Oyster Grounds & Warp \\
\hline Correlation & 0.190 & 0.080 & -0.030 & 0.150 \\
RMSE & 0.390 & 0.370 & 0.450 & 0.480 \\
$S_{\mathrm{n}}$ & 0.881 & 1.306 & 2.447 & 1.334 \\
Bias & 0.260 & 0.100 & -0.060 & -0.030 \\
Pbias & $120 \%$ & $30.4 \%$ & $39.1 \%$ & $7.3 \%$ \\
$\chi$ & 1.498 & 1.671 & 2.374 & 1.530 \\
\hline
\end{tabular}

AMM7-NE nutrients, only the model phosphate at L4 would be rated as "poor" according to the Pbias. In fact, several of the Pbias estimates for the nutrients are $<10 \%$ and could be considered as excellent.

The comparison with the WOA09 fields is not ideal because the WOA09 nutrients are also being used as boundary conditions for the AMM7-NE system and are, therefore, not independent. It would have been desirable to validate the ecosystem behaviour against a wider range of in situ observations including sub-surface observations throughout the domain. Further efforts are being made to validate the model fields against in situ data from other sources including zooplankton and phytoplankton biomass data from the Sir Alister Hardy Foundation for Ocean Science (SAHFOS) and cruise data for nutrients and chlorophyll from the Institute of Marine Research (IMR) in Norway. Additional collaboration with Cefas and the Agri-Food and Biosciences Institute (AFBI) in Northern Ireland will result in further validation efforts within the NWS region.

The AMM7-NE system seems to have solved the main problems with the nutrient dynamics in the MRCS-PE system as discussed in Siddorn et al. (2007). As can be seen in Figs. 3 through 6 and the statistics provided (Tables 1 and 2), the annual cycle of nutrient levels is much improved throughout the domain. This is apparent in both the winter nutrient levels and the draw-down of the nutrients in spring and summer. In Fig. 6 of this paper along with Figs. $4 c$ and 5c from Siddorn et al. (2007), it is easy to see that there was an underestimation of the nutrient depletion in summer months in the MRCS-PE system that is no longer apparent in the AMM7NE system. This may have contributed to the MRCS-PE system problem with the accumulation of nutrients throughout the domain over time. This problem appears to be solved and was possibly partly due to the size of the domain itself which extended only to the $200 \mathrm{~m}$ isobath along with the zero flux boundary conditions that were applied. As mentioned in Sect. 2.1, with the AMM7 domain the boundaries are further from the shelf in the new system, WOA09 values are used to force the nutrients at the model edge. Additionally, the higher vertical resolution in the AMM7-NE is likely to have improved the resolution of the nutricline considerably and therefore contributed to the improvement of the surface nu- trient fields and consequently the limitation of primary production in the growing season.

The distinct feature seen in the Figs. 3, 4, 5 and 9 shows the spatial distribution of nutrients and chlorophyll, which characteristically follow the shelf edge current (SEC) that flows around the continental margins. The eastern North Atlantic water (ENAW), which forms in the Bay of Biscay (Pollard et al., 1996), is advected northwards, around the Porcupine Bank into the southern Rockall Trough (Ellett and Martin, 1973; New et al., 2001) by the poleward SEC. The irregular shape of the European shelf, with capes, canyons, and varying shelf width, can cause locally enhanced up/downwelling and cross-slope flow (Throwbridge et al., 1998). Hence as mentioned above, we believe the excess of nutrients depicted in the above figures is partially caused by excess upwelling in the NEMO model along the steep slopes in these regions.

Figure 9 also highlights an unrealistic winter chlorophyll maximum in the model west of Iberia which is likely due to the use of WOA nutrient boundary conditions with no related boundary condition for either chlorophyll or phytoplankton. However, as mentioned earlier, the modelling of the off-shelf regions, including the waters off the Iberian Peninsula, is not the aim of the work. These areas merely serve to drive the improved on-shelf dynamics which is our focus. We are currently exploring several options for improved boundary conditions within ERSEM including climatological chlorophyll fields or fields from a global biogeochemical model which is being run pre-operationally at the Met Office, with eventually two-way nesting into the larger domain model.

To understand the differences in the effects of moving to a larger domain versus the change in boundary conditions for the nutrient fields, an additional experiment was performed which used the old boundary conditions (zeroflux) on the new AMM7-NE domain. This experiment included the same one year spin-up and two year hindcast as the other model runs. The only difference was the application of zero-flux boundary conditions for the nutrients instead of WOA09 values. The effect of the WOA09 boundary conditions can be seen in Fig. 11 which compares the monthly average AMM7-NE model for December 2008 with (Fig. 11, left) and without (Fig. 11, right) WOA09 nitrate values applied at the boundaries with the WOA09 December climatological field (Fig. 11, centre). In the northeastern part of the domain, the improvement through the use of the boundary conditions is most apparent. While the cost function for the model runs with and without the WOA09 boundary values are both $<1.0$, a comparison of the statistics calculated using seasonal averages for the AMM7-NE model shows an improvement with the WOA09 boundary conditions $(\chi=$ 0.682 versus 0.808 ; correlations: 0.643 versus 0.416 ; RMSE of $2.72 \mathrm{mmol} \mathrm{m}^{-3}$ versus $3.23 \mathrm{mmol} \mathrm{m}^{-3}$ ). The bias switches signs between the two runs with a negative bias (indicating higher nutrient values in the model relative to the climatology) of $-1.08 \mathrm{mmol} \mathrm{m}^{-3}$ in the run with WOA09 boundary conditions to a positive bias (indicating lower nutrient values 

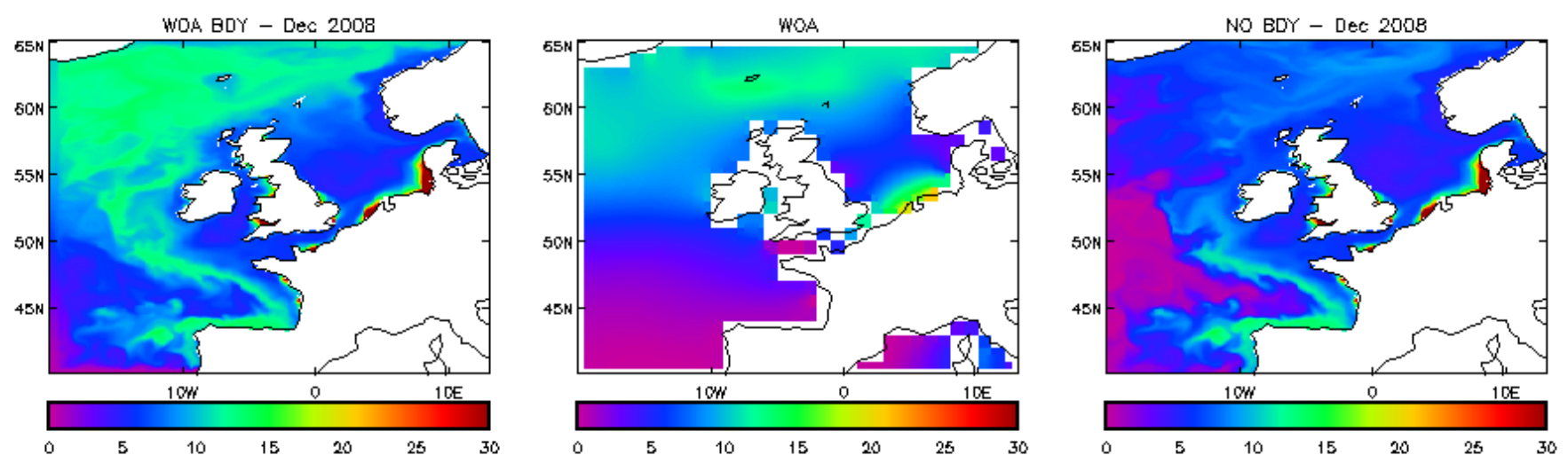

Fig. 11. Monthly average surface nitrate values $\left(\mathrm{mmol} \mathrm{m}^{-3}\right)$ for the AMM7-NE model with WOA09 BDY (left) and without WOA09 boundary conditions (right) compared with the climatological value (centre). The model fields are from December 2008.

in the model relative to climatology) of $+0.74 \mathrm{mmol} \mathrm{m}^{-3}$ without boundary conditions. The AMM7 domain appears to rely on nutrient influx from the northeast Atlantic Ocean, especially during the winter months, and in fact, the positive bias in the model run without WOA09 boundary conditions increases from a value of $+0.34 \mathrm{mmol} \mathrm{m}^{-3}$ in 2007 to $+1.11 \mathrm{mmol} \mathrm{m}^{-3}$ in 2008 .

While the new AMM7-NE system now has approximately the correct amount of chlorophyll in total over the MRCS domain and the two-year hindcast period (represented by the bias of 0.009 and Pbias of $16.4 \%$ in Table 3), the spatial distribution and timing of that chlorophyll warrants additional investigation. There are also marked differences in the performance of the sub-regions within the model domain with the best correspondence in the English Channel region, as shown in Fig. 2, which includes the L4 site. The cost function versus satellite data in the English Channel region is slightly $>1.0$ at 1.05 and is 1.4 versus the in situ data at L4. The Norwegian Trench and southern North Sea also provide a good approximation to the satellite chlorophyll while the off-shelf region, in general, has too much chlorophyll throughout the spring and summer as shown in the Taylor plots in Fig. 8. Further investigation into the timing and succession of the phytoplankton functional groups is necessary and is being planned.

Improvements to both the NEMO and ERSEM models are being investigated which should have an impact on the biogeochemical cycles within ERSEM. Due to the challenges of acquiring river data in near real-time (NRT) for use in the operational model, the use of a hydrological model to replace the current climatological river outflows, temperature and nutrient values is being investigated. Additionally, the replacement of the current specification of a climatological Baltic boundary with real-time data from a Baltic model is under consideration. Improvements to the light attenuation scheme are also being investigated including the use of a three-band scheme and spatial variation of the light attenuation coefficient based on satellite observations. The non-operational
POLCOMS-ERSEM system in development at PML and the National Oceanography Centre in Liverpool (NOCL) uses satellite inherent optical properties within ERSEM which has been shown to have a positive impact on the model chlorophyll fields (Wakelin et al., 2012). In the long-term, work is being done to improve the ecosystem model further by including data assimilation of the chlorophyll field from satellite data (Ciavatta et al., 2011) and to include the satellite optical information as used in the POLCOMS-ERSEM system in either NRT or as climatological input for the AMM7-NE system.

\section{Conclusions}

The AMM7-NE system has been shown to be an effective modelling tool which demonstrates an increasing amount of skill in the European NWS domain. As discussed by Skogen and Moll (2005), the choice of the physical model on the biogeochemistry is very important. For our new operational system, O'Dea et al. (2012) provide a domain-wide validation of the AMM7-NE tides, SST and salinity fields. They find that, in general, the AMM7-NE is better than or equal to POLCOMS-AMM for SSH amplitude and phase, while the annual RMSE in SST in AMM7-NE without data assimilation is similar to POLCOMS-AMM, but with areas and seasons of weakness and strengths in each. The addition of SST data assimilation in AMM7-NE markedly reduces these errors. Additionally, O'Neill et al. (2012) provide a validation of the AMM7-NE temperature and salinity fields in Liverpool Bay and the Irish Sea in comparison with two POLCOMS systems: the $12 \mathrm{~km}$ AMM model and a $1.8 \mathrm{~km}$ Irish Sea model. While the $1.8 \mathrm{~km}$ Irish Sea model is the only one of the three that is capable of representing the small-scale coastal physics, they found that the AMM7-NE system performed as well as the $1.8 \mathrm{~km}$ POLCOMS model when using the same forcing dataset and that the AMM7-NE system better captured the Liverpool Bay tidal variability. 
For an operational system, trade-offs between domain size and resolution are necessary to ensure that the model runs within the time-frame allowed. Holt et al. (2012) conclude that primary production on the shelf is largely controlled by nutrient supply from off-shelf areas and hence, there is no hope of getting the production right without including offshelf areas at any resolution. This conclusion is supported by our experiments which result in improvements in the on-shelf nutrients with the AMM7 domain and the use of WOA09 boundary conditions for the nutrients. On the other side, it is clear that the in-shore and estuarine areas, along with the shelf-exchange processes themselves require as high resolution as possible in the scales currently feasible. As discussed above, O'Neill et al. (2012) find that the AMM7-NE system performs well compared with the high-resolution POLCOMS model, so that the resulting AMM7-NE system provides for the best tractable resolution over a domain that includes the shelf-break and connected off-shelf areas.

In the AMM7-NE system, the nutrient fields throughout the domain are much improved, while there is potential for further improvements in the chlorophyll field. The system can be used to extend the products and projects already developed using the MRCS-PE system, such as the nuisance bloom prediction tool for the Environment Agency (Mahdon et al., 2010; Barciela et al., 2012), and to provide derived products such as annual or seasonal mean primary productivity and OSPAR-like eutrophication indices. As part of the operational system at the Met Office, the AMM7-NE is regularly delivering products through MyOcean and to other users such as the UK Royal Navy. The need for operational ecosystem models for fisheries and environmental scientists has been highlighted recently by Berx et al. (2011) along with the further potential for using these types of models for spatial management decisions in the marine environment (Janssen et al., 2011) and the use of the AMM7-NE system in such management context is being explored. With further improvements and longer-term validation to assess the ability of the model to reproduce both the seasonal signal (as shown herein) and inter annual variability, this system could become a component of an integrated model and observation-based monitoring system for the coastal regions around the UK and could potentially be used to provide input to a climate status assessment of the NWS region.

Acknowledgements. Thanks to the Centre de Recherche et d'Exploitation Satellitaire (CERSAT), at Ifremer, Plouzané (France) for providing the satellite data though MyOcean. Thanks also to Cefas, UK for providing the SmartBuoy data through their website database archive. Funding for this research is gratefully acknowledged from the Ministry of Defence, from the European Community's Seventh Framework Programme FP7/2007-2013 under grant agreement no. 218812 (MyOcean) and from Ocean2025: the NERC's core programme in ocean science. Thanks also to Mike Bell who provided comments on this manuscript.

Edited by: J. A. Johannessen

\section{References}

Allen, J. I., Holt, J. T., Blackford, J., and Proctor, R.: Error quantification of a high-resolution coupled hydrodynamic-ecosystem coastal-ocean model: Part 2. Chlorophyll-a, nutrients and SPM, J. Mar. Syst., 68, 381-404, doi:10.1016/j.jmarsys.2007.01.005, 2007.

Barciela, R., Mahdon, R., Edwards, K., Miller, P., Shutler, J., Jonas, P., Murdoch, N., Whither, A., and Roast, S.: Operational monitoring and forecasting of water quality through combining a model, satellite Earth observations and in situ sampling: the AlgaRisk initiative, in preparation, 2012.

Baretta, J. W., Admiraal, C. F., Malschaert, J. F. P., and Ruardij, P.: The construction of the pelagic submodel, in: Tidal flat estuaries: Simulation and analysis of the Ems estuary, edited by: Baretta, J W. and Ruardij, P., Springer-Verlag, Heidelberg, 77-104, 1988.

Baretta, J. W., Ebenhoh, W., and Ruardij, P.: The EuropeanRegional-Seas-Ecosystem-Model, a complex marine ecosystem model, Neth. J. Sea. Res., 33, 233-246, 1995.

Berx, B., Dickey-Collas, M., Skogen, M. D., De Roeck, Y.-H., Klein, H., Barciela, R., Forster, R. M., Dombrowsky, E., Huret, M., Payne, M., Sagarminaga, Y., and Schrum, C: Does operational oceanography address the needs of fisheries and applied environmental scientists?, Oceanography, 24, 166-171, 2011.

Blackford, J. C., Allen, J. I., and Gilbert, F. J.: Ecosystem dynamics at six contrasting sites: A generic modelling study, J. Marine Syst., 52, 191-215, doi:10.1016/j.jmarsys.2004.02.004, 2004.

Butenschön, M., Holt, J., Artioli, Y., Wakelin, S. L., Saux-Picart, S., de Mora, L., Blackford, J., and Allen, J. I.: A Biogeography of the seasonal phytoplankton dynamics in the north-west European shelf seas, in preparation, 2012.

Ciavatta, S., Torres, R., Saux-Picart, S., and Allen, J. I.: Can ocean color assimilation improve biogeochemical hindcasts in shelf seas?, J. Geophys. Res.-Oceans, 116, C12043, doi:10.1029/2011JC007219, 2011.

Craig, P. D. and Banner, M. L.: Modeling wave-enhanced turbulence in the ocean surface-layer, J. Phys. Oceanogr., 24, 25462559, 1994.

de Rada, S., Arnone, R. A., and Anderson, S.: Bio-physical ocean modeling in the Gulf of Mexico, OCEANS, 1-3, 1-7, 2009.

Ellett, D. J. and Martin, J. H. A.: The physical and chemical oceanography of the Rockall Channel, Deep-Sea Res., 20, 585625, 1973.

Garcia, H. E., Locarnini, R. A., Boyer, T. P., Antonov, J. I., Zweng, M. M., Baranova, O. K., and Johnson, D. R.: World ocean atlas 2009, volume 4: Nutrients (phosphate, nitrate, silicate), Noaa atlas Nesdis 71, edited by: Levitus, S., US Government Printing Office, Washington, D.C., 398 pp., 2010.

Gattuso, J. P., Frankignoulle, M., and Wollast, R.: Carbon and carbonate metabolism in coastal aquatic ecosystems, Annu. Rev. Ecol. Syst., 29, 405-434, 1998.

Geider, R. J., MacIntyre, H. L., and Kana, T. M.: Dynamic model of phytoplankton growth and acclimation: Responses of the balanced growth rate and the chlorophyll a:Carbon ratio to light, nutrient-limitation and temperature, Mar. Ecol.-Prog. Ser., 148, 187-200, 1997.

Glibert, P. M., Allen, J. I., Bouwman, A. F., Brown, C. W., Flynn, K. J., Lewitus, A. J., and Madden, C. J.: Modeling of HABs and eutrophication status, advances, challenges, J. Marine Syst., 83, 262-275, doi:10.1016/j.jmarsys.2010.05.004, 2010. 
Gohin, F., Druon, J. N., and Lampert, L.: A five channel chlorophyll concentration algorithm applied to SeaWifs data processed by SeaDas in coastal waters, Int. J. Remote Sens., 23, 1639-1661, doi:10.1080/01431160110071879, 2002.

Gohin, F., Loyer, S., Lunven, M., Labry, C., Froidefond, J. M., Delmas, D., Huret, M., and Herbland, A.: Satellite-derived parameters for biological modelling in coastal waters: Illustration over the eastern continental shelf of the Bay of Biscay, Remote Sens. Environ., 95, 29-46, doi:10.1016/j.rse.2004.11.007, 2005.

Green, D., Uccellini, L., Colton, M., Turner, E., Scheurer, D., Valette-Silver, N., Matlock, G., Brown, C. W., and Wilson, D.: Toward a marine ecological forecasting system, OCEANS, 1-3, 2210-2215, 2009.

Holt, J. T. and James, I. D.: An s coordinate density evolving model of the Northwest European continental shelf - 1, model description and density structure, J. Geophys. Res.-Oceans, 106, 1401514034, 2001.

Holt, J. T., Allen, J. I., Proctor, R., and Gilbert, F.: Error quantification of a high-resolution coupled hydrodynamic-ecosystem coastal-ocean model: Part 1 model overview and assessment of the hydrodynamics, J. Marine Syst., 57, 167-188, doi:10.1016/j.jmarsys.2005.04.008, 2005.

Holt, J., Harel, J., Proctor, R., Michel, S., Ashworth, M., Batstone, C., Allen, J. I., Holmes, R., Smyth, T. J., Haines, K., Bretherton, D., and Smith, G.: Modelling the global coastal ocean, Philosophical Transactions of the Royal Society A, 367, 939-951, 2009.

Holt, J., Butenschön, M., Wakelin, S. L., Artioli, Y., and Allen, J. I.: Oceanic controls on the primary production of the northwest European continental shelf: model experiments under recent past conditions and a potential future scenario, Biogeosciences, 9, 97-117, doi:10.5194/bg-9-97-2012, 2012.

Janssen, F., Edwards, K. P., and Tian, T.: The potential use of operational models in marine spatial management, ICES Annual Science Conference, Gdansk, Poland, 2011.

Jolliff, J. K., Kindle, J. C., Shulman, I., Penta, B., Friedrichs, M. A. M., Helber, R., and Arnone, R. A.: Summary diagrams for coupled hydrodynamic-ecosystem model skill assessment, J. Marine Syst., 76, 64-82, doi:10.1016/j.jmarsys.2008.05.014, 2009.

Justic, D., Bierman, V. J., Scavia, D., and Hetland, R. D.: Forecasting Gulf's hypoxia: The next 50 years?, Estuar Coast, 30, 791801, 2007.

Kelly-Gerreyn, B. A., Hydes, D. J., Hartman, M. C., Siddorn, J., Hyder, P., and Holt, M. W.: The phosphoric acid leak from the wreck of the MV Ece in the English Channel in 2006: Assessment with a ship of opportunity, an operational ecosystem model and historical data, Mar. Pollut. Bull., 54, 850-862, doi:10.1016/j.marpolbul.2007.04.020, 2007.

Lazzari, P., Teruzzi, A., Salon, S., Campagna, S., Calonaci, C., Colella, S., Tonani, M., and Crise, A.: Pre-operational short-term forecasts for Mediterranean Sea biogeochemistry, Ocean Sci., 6, 25-39, doi:10.5194/os-6-25-2010, 2010.

Levier, B., Treguier, A. M., Madec, G., and Garnier, V.: Free surface and variable volume in the NEMO code, MERSEA IP report WP09-CNRS-STR03-1A, 47 pp., 2007.

Longhurst, A., Sathyendranath, S., Platt, T., and Caverhill, C.: An estimate of global primary production in the ocean from satellite radiometer data, J. Plankton Res., 17, 1245-1271, 1995.
Madec, G.: NEMO ocean engine, Institut Pierre-Simon Laplace (IPSL), France, 2008.

Mahdon, R., Edwards, K. P., Barciela, R., Miller, P., Shutler, J. D., Roast, S., Jonas, P., Murdoch, N., and Wither, A.: Advances in operational ecosystem modelling and the prediction of nuisance algal blooms, ICES Annual Science Conference, Nantes, France, 2010.

Martin, A. J., Hines, A., and Bell, M. J.: Data assimilation in the FOAM operational short-range ocean forecasting system: A description of the scheme and its impact, Q. J. Roy. Meteorol. Soc., 133, 981-995, doi:10.1002/Qj.74, 2007.

McGillicuddy, D. J.: Models of harmful algal blooms conceptual, empirical, and numerical approaches preface, J. Marine Syst., 83, 105-107, doi:10.1016/j.jmarsys.2010.06.008, 2010.

Moll, A. and Radach, G.: Review of three-dimensional ecological modelling related to the North Sea shelf system - part 1: Models and their results, Prog. Oceanogr., 57, 175-217, doi:10.1016/S0079-6611(03)00067-3, 2003.

New, A. L., Barnard, S., Herrmann, P., and Molines, J. M.: On the origin and pathway of the saline inflow to the Nordic Seas: Insights from models, Prog. Oceanogr., 48, 255-287, 2001.

Nobre, A. M., Ferreira, J. G., Newton, A., Simas, T., Icely, J. D., and Neves, R.: Management of coastal eutrophication: Integration of field data, ecosystem-scale simulations and screening models, J. Marine Syst., 56, 375-390, doi:10.1016/j.jmarsys.2005.03.003, 2005.

O’Dea, E. J., Arnold, A. K., Edwards, K. P., Furner, R., Holt, J. T., Hyder, P., Liu, H., Martin, M. J., Siddorn, J. R., Storkey, D., and While, J.: An operational ocean forecast system incorporating NEMO and SST data assimilation for the tidally driven european north-west shelf, J. Oper. Oceanogr., 5, 3-17, 2012.

O’Neill, C. K., Polton, J. A., Holt, J. T., and O’Dea, E. J.: Modelling temperature and salinity in Liverpool Bay and the Irish Sea: sensitivity to model type and surface forcing, Ocean Sci., 8, 903-913, doi:10.5194/os-8-903-2012, 2012.

Pauly, D. and Christensen, V.: Primary production required to sustain global fisheries (vol 374, pg 255, 1995), Nature, 376, 279279, 1995.

Petihakis, G., Smith, C. J., Triantafyllou, G., Sourlantzis, G., Papadopoulou, K. N., Pollani, A., and Korres, G.: Scenario testing of fisheries management strategies using a high resolution ERSEM-POM ecosystem model, Ices J. Mar. Sci., 64, 16271640, 2007.

Pinardi, N. and Coppini, G.: Preface "Operational oceanography in the Mediterranean Sea: the second stage of development", Ocean Sci., 6, 263-267, doi:10.5194/os-6-263-2010, 2010.

Pollard, R. T., Griffiths, M. J., Cunningham, S. A., Read, J. F., Perez, F. F., and Rios, A. F.: Vivaldi 1991-a study of the formation, circulation and ventilation of Eastern North Atlantic Central Water, Prog. Oceanogr., 37, 167-192, 1996.

Popova, E. E., Lozano, C. J., Srokosz, M. A., Fasham, M. J. R., Haley, P. J., and Robinson, A. R.: Coupled 3d physical and biological modelling of the mesoscale variability observed in North-east Atlantic in Spring 1997: Biological processes, Deep-Sea Res. Pt. I, 49, 1741-1768, 2002.

Proctor, R., Holt, J. T., Allen, J. I., and Blackford, J.: Nutrient fluxes and budgets for the North West European Shelf from a three-dimensional model, Sci. Total Environ., 314, 769-785, doi:10.1016/S0048-9697(03)00083-4, 2003. 
Roiha, P., Westerlund, A., Nummelin, A., and Stipa, T.: Ensemble forecasting of harmful algal blooms in the Baltic Sea, J. Marine Syst., 83, 210-220, doi:10.1016/j.jmarsys.2010.02.015, 2010.

Russo, A., Coluccelli, A., Iermano, I., Falcieri, F., Ravaioli, M., Bortoluzzi, G., Focaccia, P., Stanghellini, G., Ferrari, C. R., Chiggiato, J., and Deserti, M.: An operational system for forecasting hypoxic events in the Northern Adriatic Sea, Geofizika, 26, 191-213, 2009.

Sathyendranath, S., Stuart, V., Nair, A., Oka, K., Nakane, T., Bouman, H., Forget, M. H., Maass, H., and Platt, T.: Carbonto-chlorophyll ratio and growth rate of phytoplankton in the sea, Mar. Ecol.-Prog. Ser., 383, 73-84, doi:10.3354/Meps07998, 2009.

Siddorn, J. R., Allen, J. I., Blackford, J. C., Gilbert, F. J., Holt, J. T., Holt, M. W., Osborne, J. P., Proctor, R., and Mills, D. K.: Modelling the hydrodynamics and ecosystem of the North-west European Continental Shelf for operational oceanography, J. Marine Syst., 65, 417-429, doi:10.1016/j.jmarsys.2006.01.018, 2007.

Skogen, M. D. and Moll, A.: Importance of ocean circulation in ecological modeling: An example from the North Sea, J. Marine Syst., 57, 289-300, 2005.

Smith, S. V. and Hollibaugh, J. T.: Coastal metabolism and the oceanic organic-carbon balance, Rev. Geophys., 31, 75-89, 1993.

Smyth, T. J., Fishwick, J. R., Al-Moosawi, L., Cummings, D. G., Harris, C., Kitidis, V., Rees, A., Martinez-Vicente, V., and Woodward, E. M. S.: A broad spatio-temporal view of the Western English Channel Observatory, J. Plankton Res., 32, 585-601, doi:10.1093/plankt/fbp128, 2010.

Song, Y. H. and Haidvogel, D.: A semi-implicit ocean circulation model using a generalized topography-following coordinate system, J. Comput. Phys., 115, 228-244, 1994.

Souza, A. J., Holt, J. T., and Proctor, R.: Modelling SPM on the Northwest European Shelf Seas., in: Coastal and shelf sediment transport, edited by: Balson, P. and Colins, M., The Geological Society, London, 2007.
Storkey, D., Blockley, E. W., Furner, R., Guiavarc'h, C., Lea, D., Martin, M. J., Barciela, R. M., Hines, A., Hyder, P., and Siddorn, J. R.: Forecasting the ocean state using NEMO: The new FOAM system, J. Oper. Oceanogr., 3, 3-15, 2010.

Sykes, P. A. and Barciela, R. M.: Assessment and development of a sediment model within an operational system, J. Geophys. Res., 117, C04036, doi:10.1029/2011JC007420, 2012.

Taylor, K. E.: Summarizing multiple aspects of model performance in a single diagram, J. Geophys. Res.-Atmos., 106, 7183-7192, 2001.

Throwbridge, J. H., Chapman, D. C., and Candela, J.: Topographic effects, straits and the bottom boundary layer, in: The Sea, edited by: Brink, K. H. and Robinson, A. R., 63-88, 1998.

Tsagaraki, T. M., Petihakis, G., Tsiaras, K., Triantafyllou, G., Tsapakis, M., Korres, G., Kakagiannis, G., Frangoulis, C., and Karakassis, I.: Beyond the cage: Ecosystem modelling for impact evaluation in aquaculture, Ecol Model, 222, 2512-2523, doi:10.1016/j.ecolmodel.2010.11.027, 2011.

Umlauf, L. and Burchard, H.: A generic length-scale equation for geophysical turbulence models, J. Mar. Res., 61, 235-265, 2003.

Wakelin, S. L., Holt, J. T., Blackford, J. C., Allen, J. I., Butenschön, M., and Artioli, Y.: Modeling the carbon fluxes of the northwest European continental shelf: Validation and budgets, J. Geophys. Res., 117, C05020, doi:10.1029/2011JC007402, 2012.

Wild-Allen, K., Herzfeld, M., Thompson, P. A., Rosebrock, U., Parslow, J., and Volkman, J. K.: Applied coastal biogeochemical modelling to quantify the environmental impact of fish farm nutrients and inform managers, J. Marine Syst., 81, 134-147, doi:10.1016/j.jmarsys.2009.12.013, 2010.

Young, E. F. and Holt, J. T.: Prediction and analysis of long-term variability of temperature and salinity in the Irish Sea, J. Geophys. Res.-Oceans, 112, C01008, doi:10.1029/2005jc003386, 2007. 